DYNAMIC FORECASTING OF TRAVEL

DEMAND, RESIDENTIAL LOCATION

AND LAND DEVELOPMENT

\author{
Alex Anas* \\ Liang Shyong Duann** \\ September, 1983 \\ CP-83-45 \\ * Northwestern University, \\ Evanston, Illinois, U.S.A. 60201 \\ ** National Cheng Kung University, \\ Tainan, Taiwan, R.O.C.
}

Contributions to the Metropolitan Study: 1

This paper was presented at an IIASA Seminar on July 20, 1983 and was prepared for the Eighth

Pacific Regional Science Conference, August 17-19, 1983 in Tokyo, Japan.

Colzaborative Papers report work which has not been performed solely at the International Institute for Applied Systems Analysis and which has received only limited review. Views or opinions expressed herein do not necessarily represent those of the Institute, its National Member Organizations, or other organizations supporting the work.

INTERNATIONAL INSTITUTE FOR APPLIED SYSTEMS ANALYSIS A-2361 Laxenburg, Austria 
FOREWORD

The project "Nested Dynamics of Metropolitan Processes and Policies" was initiated by the Regional $\varepsilon$ Urban Development Group in 1982, and the work on this collaborative study started in 1983.

The series "Contributions to the Metropolitan Study" is a means of conveying information between the collaborators in the network of the project.

This paper is the first of these contributions and presents the CATLAS-model (The Chicago Area Transportation-Land Use

Analysis system) which is a dynamic large-scale urban simulation model for forecasting the effect of transportation system changes on travel mode choices, residential location, housing values and housing stock adjustment.

CATLAS has been applied to cost-benefit analysis of several subway projects proposed for the southwest side of Chicago. Currently, the model is being implemented to analyze the transportation system in stockholm, and plans exist to extend this type of cross-city implementation to several other regions in the project.

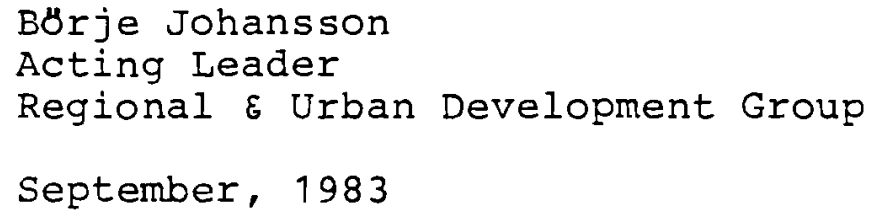


CONTENTS

1. INTRODUCTION AND SUMMARY 1

2. THE STRUCTURE AND PROPERTIES OF CATLAS 6

2.1. Overall Recursive-Dynamic Structure 6

2.2. The Demand Submodel 10

2.3. The Occupancy or Existing Housing Supply
Submodel

2.4. The Housing Stock Adjustment Submodels 14

2.5. Market Clearing Equilibrium at Each Year 16

2.6. Steady State Behavior of CATLAS 17

3. EMPIRICAL ESTIMATION 18

3.1. Data Sampling and Estimation 18

3.2. Estimation of Demand Submodels 18

$\begin{array}{ll}\text { 3.3. Estimation of Occupancy and Stock Adjustment } & \\ \text { Submodels } & 19\end{array}$

4. SIMULATIONS AND POLICY IMPLICATIONS 20

4.1. Simulation Data and Assumptions 20

4.2. Simulation Results and Transit Finance

4.2.1. Static Simulations $\quad 22$

4.2.2. Dynamic Simulations 23

4.3. Caveats and Conclusions 26

$\begin{array}{ll}\text { REFERENCES } & 28\end{array}$

FIGURES 1-5 30-34

TABLES $1-11$ 35-45 


\section{INTRODUCT ION AND SUMMARY}

It is well known that following a transportation improvement (or more generally any infrastructure investment), the prices of real estate near the improvement will increase due to the increase in accessibility and the quality of service and the decrease in travel time.

However, there is a gap in our knowledge of how to estimate property value increases caused by a public investment. Urban economists have developed simplified mathematical models of long run equilibrium in the urban land and real estate markets. These models provide a sound theoretical basis for policy analysis but are not detailed enough for actual empirical application. On the other hand, transportation planners place a strong emphasis on empirically estimable models, but these models focus only on the travel-related attributes and the demand for travel without properly taking into account the interactions between transportation, land use and property values through the markets for land and buildings.

There is a need for a theoretically sound and empirically estimable dynamic model which can satisfy the transportation planner's travel demand forecasting requirements while at the same time predicting the operation of real estate markets and the adjustment in property values due to new or improved transportation systems.

The Chicago Area Transportation/Land Use Analysis System (CATLAS) is such a model which synthesizes our knowledge of "location rent analysis" from urban economics with our knowledge of "travel demand analysis" from transportation planning. It is a dynamic model which simulates the market in recursive periods of one year in length, and for a geographic grid system of 1690 zones covering the Chicago metropolitan area. The distribution of jobs among the zones and the 
characteristics of the transportation system are assumed to be known in every year. CATLAS generates people's choices of travel mode (automobile, commuter rail, rail rapid transit, bus, and "other") and their choice of residential location. Transportation improvements or changes in parking fees, gas prices, transit fares, etc. change people's decisions of where they will live and how they will commute there, given where they work. This is a demand side process and it is assumed that people make their decisions rationally by choosing the most attractive (or utility maximizing) of the travel-location options available. Because people are different, their choices differ as well. On the supply side CATLAS simulates profit-maximizing behavior on the part of housing owners. Three decisions are simulated. For the owner of an existing dwelling unit the decision (which recurs every year) is whether to withdraw the dwelling from the market and keep it vacant or whether to supply it to the market by selling it or renting it out. For the owner of vacant land, the decision is whether to build new housing on that land or whether to postpone that decision to the next year. The owner of an old dwelling or building faces a similar decision. If he perceives that demolishing the building and selling the land is more profitable than continuing to rent it out he will demolish and sell. Otherwise the decision will be postponed to the next year. Building new dwellings and demolishing old ones are major decisions that take time to implement. In CATLAS it is assumed that there is a one year lag: the number of new dwellings constructed and old ones demolished in a given year depend on decisions based on last year's conditions. The demand and supply side of a real estate market must be in some sort of balance. This balance comes about as prices and rents adjust in each geographic zone. In CATLAS it is assumed that the demand for occupancy in a zone in a given year equals the number of dwellings supplied for occupancy in that year. Prices and rents adjust within 
every year to make this possible. Such a clearing of the market is a "temporary equilibrium". Changes in outside influences such as travel characteristics or job locations will shift the system to a new "temporary equilibrium" next year.

A precise list of the simulation output of the current version of CATLAS is as follows:

(1) the average housing rent in each geographic zone in each year,

(2) the number of vacant dwellings in each geographic zone in each year,

(3) the number of commuters choosing each travel mode by geographic zone of residence and employment,

(4) the number of new twellings built by zone in each year,

(5) the number of old dwellings demolished by zone in each year,

(6) the price of the vacant land in each zone in each year,

(7) the amount of vacant land in each zone in each year,

(8) the number of dwellings in each zone in each year,

(9) the change in aggregate housing and land rent (or producer surplus) by year and zone.

There are five lines of literature that are relevant to the subject matter of CATLAS. These are: (a) the theoretical literature on location and land use in urban economics; (b) empirical studies of the impact of transportation improvements on property values; (c) travel mode and location choice models, (d) economic urban simulation models and (e) noneconomic urban simulation models. The main developments and bibliographic references in each of these areas are briefly reviewed.

The theoretical literature in urban economics is based on the early works of Mohring and Harwitz (1962), Alonso (1964), Mills (1967), Muth (1969), Beckmann (1969). The basic argument of this literature is that part of consumers' savings in travel cost (and travel time) are capitalized into land 
and property values. Although travel costs are explicitly treated in this literature, travel time savings are not considered explicitly, but it is understood that the same results apply to travel times as well. In theoretical urban economic models such as those by wheaton (1974) and Arnott and Stiglitz (1981) the interest is in the relationship between uniform improvements in unit transportation costs and the aggregate value of land. Even in such cases the relationship between aggregate rents and travel costs is complicated and does not yield any simple quantitative rules of thumb.

In the empirical literature the focus is not on whether aggregate rent will increase or fall, or on how to measure benefits, but rather on how to measure the magnitude of changes in land or other real estate values following the transportation improvement. These studies generally agree that the improvement would increase values nearby. The earlier studies are descriptive. These include the impacts of rapid transit (Spengler, 1930; Davis, 1965), expressways (Adkins, 1959; Lemly, 1959; Golden, 1968), interchange development (Ashley, 1965) and interstate highways (Wootan and haning, 1960) on property values. The more recent work uses statistical analysis. Examples of these are the study of the Lindenwold-Camden-Philadelphia line by Mudge (1972) and Boyce et al. (1972), of a rapid transit line in Toronto by Dewees (1976) and of the Washington, D.C. METRO by Lerman et al. (1977). The findings of these studies ninge on the judicious application of multivariate regression analysis making substantial improvement on the descriptive studies.

A major shortcoming of all these studies is that they are exclusively focused on specific transportation facilities. Each tends to deal with a single or several selected facilities rather than attempt a region-wide or city-wide cross-sectional study of the effects of multimodal transportation systems. As a result, their findings are difficult to generalize and are biased by the 
peculiar conditions that may surround the studied facilities.

The power of mode choice analyse has increased since the contributions of (McFadden (1973) and Domencich and McFadden (1975). Transportation planners can now analyze mode choices by drawing on the standard techniques of multinomial logit, nested logit and multinomial probit models. Logit and nested logit models have also been applied to the choice of residential location and the joint choice of travel mode and residential location by Quigley (1976), Lerman (1977), McFadden (1978) and Anas (1981). The resulting models predict choices of location and travel mode but not the aggregate behavior of housing prices in response to travel improvements.

There are two economic urban simulation models which have been empirically applied to policy questions concerning the housing market. These are the Urban Institute Model (UIM) (de Leeuw and Struyk, 1975) and the National Bureau of Economic Research (NBER) (Ingram et al., 1973) model. The former model is based on a well developed theory of housing market behavior and includes a number of innovative ideas. Weaknesses of the model are (1) its highly aggregated form which makes it inapplicable to situations requiring detail, (2) the fact that it can be statistically estimated only with rather crude aggregated data and (3) that the numerical algorithm it uses may not always be able to find a solution. The NBER model is the most comprehensive urban simulation model developed. Unfortunately, it is not a very workable model because it cannot be consistently estimated since all of the data it requires is not available for the same metropolitan area. Some of its submodels are descriptive in nature and are not rooted in theory. The assignment of households to housing units follows a disequilibrium process rather than being rooted in well established market clearing procedures.

CATLAS is an economic urban simutation model primarily intended for testing 
the effects of transportation policies on housing and land values, on residential land development and on mode choice patterns. It can deal with any transportation policy which changes travel times and costs in any of several travel modes. CATLAS can be estimated in its entirety using widely available data and rigorous econometric procedures. CATLAS has well behaved solution properties and computes equilibrium allocations of households to dwellings.

CATLAS can be viewed as a synthesis of the land rent and 1 and use models developed by urban economists following Alonso (1954) with the travel and location choice models developed by transportation planners following McFadden (1973). Thus, it is a tool for simultaneously doing travel demand and land rent analysis. Using CATLAS one can evaluate the direct benefits to the users of the transportation system, the indirect benefits to nonusers, and the fiscal benefits due to changes in rent. Thus, CATLAS provides an alternative to the noneconomic urban simulation models which do not have such capabilities and which are not estimated using rigorous econometric techniques, but by means of ad hoc and sometimes partly subjective goodness-of-fit procedures.

\section{THE STRUCTURE AND PROPERTIES OF CATLAS}

\subsection{Overall Recursive-Dynamic Structure}

CATLAS consists of a number of equations to be solved simultaneously for each year in a simulation, while some of the variables entering these equations are adjusted recursively by being linked to the solution of the previous time period. Using general functional notation, the model's equations can be written as follows, where $t=1 \ldots$ T denotes the simulation year, $i=1 \ldots$ I the residential zones covering the metropolitan area and $h=1 \ldots$. the categories of employment location (or zones of employment) and $m=1 \ldots M_{j}$ the number of modes available in zone i: 


$$
\sum_{h=1}^{H} N_{h}^{t} \sum_{m=1}^{M_{i}} \delta_{i} P_{i m}^{h}\left(\bar{R}^{t}, \bar{X}^{D t}, \bar{Y}_{h}^{t}, \bar{a}_{h}\right)=S_{i}^{t} Q_{i}^{e}\left(R_{i}^{t}, \bar{X}_{i}^{S t}, \bar{B}\right) ; i=1 \ldots I,
$$

$$
\begin{aligned}
& s_{i}^{t}=s_{i}^{t-1}+C_{i}^{t-1}-D_{i}^{t-1} ; \quad i=1 \ldots I, \\
& C_{i}^{t-1}=\left(\frac{L_{i}^{t-1}}{g_{i}}\right) Q_{i}^{c}\left(R_{i s}^{t-1}, s=1 \ldots M ; \bar{X}^{S t-1}, r, \bar{Y}\right) ; i=1 \ldots I, \\
& D_{i}^{t-1}=0_{i}^{t-1} Q_{i}^{d}\left(R_{i s}^{t-1}, s=a_{i}^{t-1} \cdot . M ; \bar{x}^{S t-1}, r, \bar{\delta}\right) ; i=1 \ldots I, \\
& L_{i}^{t-1}=L_{i}^{t-2}-g_{i} C_{i}^{t-2}+g_{i} D_{i}^{t-2} ; i=1 \ldots I, \\
& 0_{i}^{t-1}=0_{i}^{t-2}-D_{i}^{t-2}+A_{i}^{t-2} ; i=1 \ldots I, \\
& R_{i s}^{t-1}=R_{i}^{t-1}+\theta\left(s-\left\{X_{i 1}^{D t-1}=X_{i 1}^{S t-1}\right\}\right) ; i=1 \ldots I, \\
& \vec{X}_{i}^{D t}=f_{1}\left(\vec{x}_{i}^{D t-1}\right) ; i=1 \ldots I \\
& \bar{x}_{i}^{S t}=f_{2}\left(\bar{x}_{i}^{S t-1}\right) ; i=1 \ldots I \text {. }
\end{aligned}
$$

The equations in (1) are the crux of the model and are solved simultaneously for every simulation year $t$ to obtain the values of the rent vector $\vec{R}^{t}=\left[R_{1}^{t}, R_{2}^{t}, \ldots, R_{I}^{t}\right]$ where $R_{j}^{t}$ is the average rent of the housing units in zone $i$ during year $t$. This average zonal rent is defined as $R_{i}^{t}=f_{j}^{t} r_{i}^{t}+\left(1-f_{j}^{t}\right) v_{j}^{t} / 10$, where $f_{i}^{t}$ is the proportion of the zone's occupied dwellings which are renter occupied in year $t, r_{j}^{t}$ the annual rental and $v_{i}^{t}$ the 
value of the owner occupied dwellings. Values are divided by ten to annualize them following a rule of thumb due to Shelton (1968) widely used by urban economists. $N_{h}^{t}$ is the number of commuters employed in location $h$ at time $t, \delta_{j}$ is zone $i$ 's ratio of households to commuters and $s_{j}^{t}$ the number of housing units in zone $i$ at time $t$. The functions $P_{i m}^{h}(\cdot)$ and $Q_{j}^{e}(\cdot)$ are the demand and supply side choice functions. $\quad P_{i m}^{h}(\cdot)$ represents a commuter's choice of residential zone $i$ and travel mode $m$ for the journey from work to home as a function of the rents, $\bar{R}^{t}$, of all the residential zones, a vector $\bar{x}^{D t}$ describing characteristics of the residential zones, another vector $\bar{Y}_{h}^{t}$ describing travel related characteristics of the zones for travel mode $m$ and employment location $h$ and a vector $\bar{a}_{h}$ of coefficients to be estimated. $p_{i m}^{h}(\cdot)$ is the average probability with which a commuter employed at $h$ will choose zone $i$ and mode $m$, or the expected proportion of commuters employed in $h$ choosing zone $i$ and mode $m$. The function $Q_{j}^{e}(\cdot)$ is the probability that the average dwelling in zone $i$ will be offered for rent by the owner given the ongoing average rent $R_{j}^{t}$, a vector of the zone's characteristics, $\bar{X}_{j}^{S t}$, relevant to the supply side, and $\bar{B}$ a vector of coefficients to be estimated. $Q_{j}^{e}(\cdot)$ is also the expected proportion of the available owellings $s_{j}^{t}$ which will be offered for rent, $1-Q_{j}^{e_{(}}(\cdot)$ being the expected proportion to remain vacant. Equation (1) states that expected demand equals expected supply in each of the $i=1 \ldots$ z zones and in each simulation year $t=1 \ldots$. It has been proven in Anas (1982) that given $N_{h}^{t}, \delta_{j}, \bar{X}^{D t}, \bar{F}_{h}^{t}, s_{j}^{t}, \bar{X}_{j}^{S t}, \bar{a}_{h}$ and $\bar{B}$ the system of equations can be solved for a unique and stable equilibrium rent vector $\bar{R}^{t}$ which clears the market in that year $t$. The second set of equations states that the number of dwellings in year $t-1$ increases by the expected number of new dwellings constructed, $c_{i}^{t}$, less the number of old dwellings demolished, $D_{j}^{t}$ during that year. Equations (3) give the expected number of 
built in year $t-1$ in zone $i: L_{j}^{t-1}$ is the quantity of vacant land available in zone $i$ and $g_{j}$ the amount of land per dwelling allowable in zone $i$ due to zoning regulations, $\left(L_{j}^{t-1 / g_{j}}\right)$ being the potential new dwellings that can be accommodated in zone $i . Q_{j}^{c}(\cdot)$ is the expected proportion of these potential dwellings that will be built in year $t-1$. This function is derived from the developer's profitability decision. It depends on the stream of annual rents per dwelling expected to accrue over the dwelling's lifetime $M$, on the vector of supply side characteristics $\bar{X}^{S t-1}$, the market interest rate $r$ and $\bar{r}$, a vector of coefficients to be estimated. Equations (4) estimate the number of demolitions, $D_{j}^{t-1}$, in year $t-1$. This is the number of old (over thirty years) dwellings, $0_{j}^{t-1}$, eligible for demolition multiplied by the expected proportion to be demolished $Q_{j}^{d}(\cdot)$. This expected proportion is a function of the stream of annual rentals that can be obtained from the average old dwelling in zone $i$ over its remaininbg lifetime, the vector of supply side characteristics $\bar{x}^{S t}-1$, the interest rate $r$ and a vector of coefficients to be estimated, $\bar{\delta}$. The age of the average old dwelling in the zone is $a_{j}^{t-1}$. Equations (5) update the amount of vacant land in a zone by accounting for land taken up by new constructions and land released by demolitions. Equations (6) adjust the number of dwellings eligible for demolition by adding, $A_{i}^{t-2}$ the number of dwellings aging into the over thirty years category and thus becoming eligible for demolition. $A_{j}^{t-2}$ is calculated from a simple cohort-survival model for housing for each zone. Equation (7) shows how the average rent of dwellings s years old can be computed by making a linear adjustment to the average rent of zone $i$. This is done by estimating a depreciation coefficient $\theta$ and multiplying this by $s-x_{i 1}^{D t-1}$ or $s-x_{i 1}^{S t-1}$ where $x_{i 1}^{D t-1}=x_{i 1}^{S t-1}$ is the age of the average dwelling in zone $i$ at time $t-l$ (in other words, the age of the average dwelling may be considered to be the first element in the vectors 
$\bar{x}^{D t-1}$ and $\left.\bar{x}^{S t-1}\right)$. Finally equations $(8)$ and $(9)$ adjust the values of some of the variables in these vectors. The changes in the age of the average owelling is one of these adjustments.

\subsection{The Demand Submodel}

The choice problem of a commuter with a given workplace $h$, is to determine the geographic zone of residence location $i$, the mode of commuting $m$, and the exact dwelling $k$ within zone $i$.

The attractiveness (or utility) of an alternative ( $i, m, k$ ) for the average commuter employed in workplace $h$ is given as,

$$
\hat{u}_{i m k}^{h}=u_{i}^{h}+u_{i m}^{h}+u_{i m k}^{h}+\varepsilon_{i m k}^{h}
$$

This equation states that attractiveness consists of four additively separable parts. The first part, $u_{j}^{h}$ measures the part of attractiveness due to characteristics which vary by zone. The second part $U_{i m}^{h}$ is the part of attractiveness due to characteristics which vary by zone and mode of commuting. The third part $U_{i m k}^{h}$ includes the part of attractiveness which varies by zone $i$, mode $m$ and dwelling $k$. In many cases when these characteristics are not observed for each dwelling but are known in the data as zone averages they will be included in $u_{j}^{h}$ or comoined with other characteristics in $u_{i m}^{h}$. The fourth part of attractiveness $\varepsilon_{i m k}^{h}$ is a random variable due to unknown (unobserved) characteristics including things like personal preference differences, random effects and errors in measurement. The probability that a commuter employed in $h$ will choose $(i, m, k)$ is given as,

$$
p_{i m k}^{h}=\operatorname{Prob} .\left[\hat{u}_{i m k}^{h}>\hat{u}_{j n s}^{h}, v(j, n, s)=(i, m, k)\right]
$$


The specific form of (11) depends on what is assumed about the random terms, $\varepsilon_{i m k}^{h}$. We follow the assumption that these error terms are correlated within zones (i.e. for different $m$ and $k$ within each $i$ ) but uncorrelated for different zones. Under this assumption the probability $p_{i m k}^{h}$ can be computed as the computationaliy tractable nested multinomial logit model. First, because utility is additively separable we can write the probability as,

$$
p_{i m k}^{h}=p_{i}^{h} \cdot p_{m \mid i}^{h} \cdot p_{k \mid i m}^{h}
$$

Here $P_{k \mid i m}^{h}$ is the conditional probability that the commuter will choose dwelling $k$, given that zone $i$ and mode $m$ have been chosen. $P_{m / j}^{h}$ is the conditional probability that the commuter will choose mode $m$ given that zone $i$ has been chosen and $p_{i}^{h}$ is the marginal probability that zone $i$ will be chosen. These probabilities are of the form

$$
p_{k \mid i m}^{h}=1 / s_{i},
$$

$$
P_{m \mid i}^{n}=\operatorname{Exp}\left(u_{i m}^{n}\right) / \sum_{n=1}^{M_{i}} \operatorname{ExP}\left(U_{i n}^{h}\right)
$$

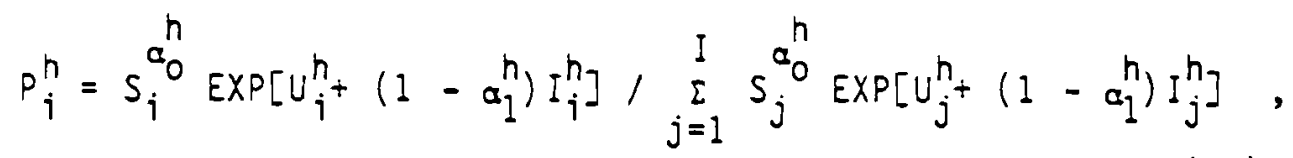

$$
I_{j}^{h}=\operatorname{LOG} \sum_{m=1}^{M_{j}} \operatorname{ExP}\left(U_{j m}^{h}\right),
$$




$$
\begin{aligned}
& U_{j m}^{h}=a_{2}^{h} \operatorname{LOG}\left(R_{j}+c_{j m}^{h}\right)+\frac{a_{3}^{h}}{a_{3 m}^{h}}, a_{2}^{h}<0, \\
& U_{j}^{h}=\frac{-h}{a_{4}} \bar{X}_{j}^{D} .
\end{aligned}
$$

Equation (13) states that dwellings within a zone are equally likely to be chosen (because the data is not detailed enough to discriminate among them). Equation (14) states that the probability of choosing a mode $m$ given the choice of zone is a multinomial logit model and thus depends on the relative attractiveness of the modes keeping zone characteristics constant.

Equation (15) is the marginal zone choice probability and this is a nested logit model adjusted for zone size measured by the number of dwellings. The zone choice probability is a function of the zone's attractiveness plus a combined measure of the attractiveness measures of the modes in that zone. The combined measure of the zone's mode attractiveness (called an "inclusive value") is given by equation (16) and is in fact the logarithm of the denominator of the mode choice model (14). Equation (17) states that the attractiveness of a zonemode combination is a function of the average zone rent plus average travel cost for the mode and also a function of other zone characteristics, $\vec{Y}_{j m}$, which include travel time, distances to stations etc. (or the logarithms of such variables).

Multiplying (14) and (15) we can compute a joint probability $p_{i m}^{h}$. This is the probability of choosing zone $i$ and mode $m$ given workplace $h$. Since all the zones are interconnected through the logit models a change in the attractiveness of a zone or the modes in that zone will have repercussions in the demand of all 
the other zones.

\subsection{The Decupancy or Existing Housing Supoly Submodel}

This submodel explains the choices of the owners of dwellings in the short run. The owner of an existing dwelling must decide whether to offer the dwelling for rent in that year or whether to withnold it until next year. The decision is based on profitability. Suppose that the average dwelling is offered for rent. Then it will yield a profit

$$
\Pi_{i 1}=R_{i}-M_{i 1}+\varepsilon_{i 1}
$$

If it is kept vacant the loss is

$$
\pi_{i 2}=-M_{i 2}+\varepsilon_{i 2}
$$

Here $R_{j}$ is the average rent in zone $i, M_{i l}$ is the cost of maintaining the average dwelling if it is occupied and $M_{j 2}$ the cost of maintaining the average dwelling if it is vacant, and $\varepsilon_{i 1}, \varepsilon_{i 2}$ are random measurement errors due to unobserved variables. Maintenance costs for occupied dwellings will be higher if the costs of repairs due to occupants exceed the costs of vandalism, neglect etc. for vacant dwellings. These will depend on the type and location of the dwelling's neighborhood. The differential profit is,

$$
\Pi_{i 1}-\pi_{i 2}=R_{i}-\left(M_{i 1}-M_{i 2}\right)+\varepsilon_{i 1}-\varepsilon_{i 2} \text {. }
$$

The differential maintenance cost is not directly available in the data but since it depends on neighborhood (i.e. zone) characteristics it can be made a function of these characteristics. Thus 


$$
\left(M_{i 1}-M_{i 2}\right)=\sum_{n=1}^{N} B_{n} x_{i n}^{S},
$$

where there are $n=1$. . N supply side zone characteristics and the $B_{n}{ }^{\prime} s$ are the coefficients to be estimated. The probability that the average dwelling will be offered for rent can now be computed as,

$$
Q_{i}^{e}=\operatorname{Prob} \cdot\left[\pi_{i 1}>\pi_{i 2}\right]
$$

The simplest model consistent with (23) is the binary logit model. In this case this is,

$$
Q_{i}^{e}=\frac{\operatorname{ExP}\left(B_{0} R_{i}+\sum_{n=1}^{N} B_{n} X_{i n}^{S}\right)}{1+\operatorname{EXP}\left(B_{0} R_{i}+\sum_{n=1}^{N} B_{n} X_{i n}^{S}\right)} \text {. }
$$

where $Q_{i}^{e}$ is the probability that the average dwelling will be offered for rent. The coefficients to be estimated are $B_{0}$ and $B_{1}, \ldots B_{N}$.

\subsection{The Housing Stock Adjustment Submodels}

Housing stock adjustments occur yearly, but only the creation of new dwellings on vacant land and the demolition of old dwellings are considered. Both of these decisions depend crucially on the "present value of profits" (FVP) that can be derived from a dwelling over its remaining lifetime. Suppose that the average dwelling lasts $M$ years and let the age of the average dwelling in zone $i$ be $a_{i}$. Then the present value of profits that accrue from rental decisions from now (time $t$ ) until $M$ can be computed as, 


$$
(P \vee P)_{t i a}=\sum_{s=a_{i}}^{M} \frac{\left(R_{i s}^{t}-M_{i 1 s}^{t}\right) Q_{i s}^{e t}+\left(-M_{i 2 s}^{t}\right)\left(1-Q_{i s}^{e t}\right)}{(1+r)^{s-a} i} .
$$

The numerator measures the "expected annual profit anticipated in the current year $t$ for the year when the dwelling is s years old." $Q_{i s}^{\text {et }}$ is the probability that the dwelling will be rented when it is s years old, computed from the occupancy submodel. In the denominator, $r$ is the market interest rate.

Now consider the owner of some vacant land parcel on which a dwelling can be constructed in zone $i$. This will be a new dwelling and thus s will run from one to $M$ in equation (25). Let $K_{i t}$ be the cost of constructing the dwelling, then the profit from construction will be,

$$
\Pi_{i c t}=(P V P)_{t i l}+J_{i M} /(1+r)^{M}-K_{i t}+\varepsilon_{i t}^{c}
$$

where $J_{i M}$ is the resale, value of the constructed dwelling M years from now and $K_{i t}$ is the current cost of constructing the dwelling, $\varepsilon_{i t}^{c}$ being a random error term. If the land is kept vacant the profits will be equal to the land's price less the present value of all future taxes and other expenses to be incurred on the land. The profits in this case are,

$$
\Pi_{i o t}=V_{i t}-T_{i t}+\varepsilon_{i t}^{0} \text {, }
$$

where $V_{i t}$ is the land price and $T_{i t}$ is the present value of taxes and other costs, $\varepsilon_{i t}^{0}$ being a random error term.

The present value of profits in equation (26) can be rewritten as 


$$
(P V P)_{t i 1}=\sum_{s=1}^{T} \frac{R_{i s}^{t} Q_{i s}^{e t}}{(1+r)^{s-1}}+\sum_{s=1}^{T} \frac{\left(M_{i 2 s}^{t}-M_{i 1 s}^{t}\right) Q_{i s}^{e t}-M_{i 2 s}^{t}}{(1+r)^{s-1}},
$$

where the first summation is the "present value of lifetime expected revenue" abbreviated as $(P V R)_{t i l}$ : Differential profits can now be written as,

$$
\pi_{i c t}-\pi_{i o t}=(P V R)_{t i 1}+\sum_{n=1}^{N} Y_{n} X_{i n}^{S t}+\varepsilon_{i t}^{c}-\varepsilon_{i t}^{0}
$$

where the summation stands for the second summation in (28) plus $V_{\text {it }}$ - $T_{\text {it }}$ which cannot be independently observed in the data. Thus these quantities are made a function of the supply side variables $x_{i n}^{S t}$, and $\gamma_{n}, n=1$. . N are coefficients to be estimated. Under these assumptions the probability that a vacant land parcel will be developed can be derived as a binary logit model of the form,

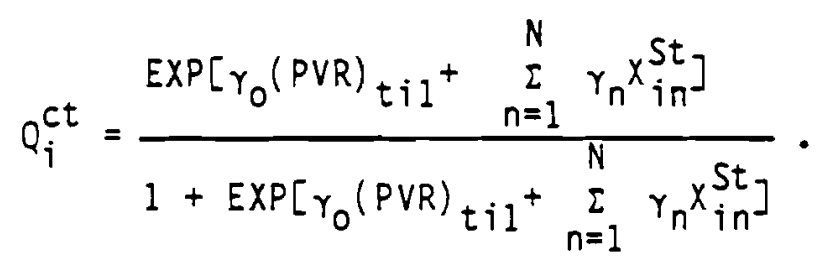

The case of demolishing an old dwelling involves a similar reasoning. In this case the probability of demolishing the average old dwelling in zone $i$ is given by the binary logit model

$$
Q_{i}^{d t}=\frac{1}{1+\operatorname{EXP}\left[\delta_{0}(P V R)_{t i}+\sum_{n=1}^{N} \delta_{n} X_{i n}^{s t}\right]},
$$

where (PVR) $t i$ is the "present value of revenue over the remaining lifetime of the average old dwelling in zone $i$ ". The o's are coefficients to be estimated.

\subsection{Market Clearing Equilibrium at Each Year}


As discussed before, the crux of the model is given by the simultaneous equations (1) which are solved for the market clearing rent vector $\bar{R}^{t}=\left[R_{1}^{t}, R_{2}^{t}, \ldots ., R_{I}^{t}\right]$ at each year $t$. For convenience, these equations are rewritten as

$$
\sum_{h=1}^{H} N_{h}^{t} \sum_{m=1}^{M_{i}} \delta_{i} P_{i m}^{h}\left(\bar{R}^{t}, \bar{X}^{D t}, \bar{C}^{t h}, \bar{T}^{t h}, \bar{Y}^{t h}, \bar{a}_{h}\right)=S_{i}^{t} Q_{i}^{e}\left(R_{i}^{t}, \bar{X}^{S t}, \bar{B}\right) .
$$

The vectors $\bar{C}^{\text {th }}, \bar{T}^{\text {th }}$, and $\bar{Y}^{\text {th }}$ contain the travel cost, travel time and other transportation system characteristics (such as station locations, parking availability, etc.). It is proven in Anas (1982) that equations (32) yield a unique equilibrium solution except possibly in the very unusual case when the rent of one or more zones are zero. This case should not be encountered in a meaningful empirical application and is thus not troublesome. It is also proven that the unique equilibrium is globally stable except for very large shifts in rents. Stability in this context means that if some rents are changed so that the system moves out of equilibrium it will return to it.

Anas (1982) also discusses a computational algorithm for solving the system of equations and finding the equilibrium zone rents. This algorithm is the one used in CATLAS to obtain the results to be reported in section 4 .

\subsection{Steady State Behavior of CATLAS}

An important aspect of dynamic tools such as CATLAS is their behavior at steady state. CATLAS produces changes in the housing stock and in the rent of each zone as well as in the age distribution of the housing stock by zone. If the inputs remain constant over time, then the annual predictions of CATLAS will converge to a long run steady state. In the long run the number of vacancies in each zone will be reduced to zero as excess dwellings which remain vacant year after year will become demolished. All other variables determined within the 
model will either converge to steady state values or will cycle around a steady state value (i.e. will converge to a limit cycle).

\section{EMPIR ICAL ESTIMATION}

In this section we briefly discuss the data ano how it was used to estimate the four submodels of CATLAS. The estimation results for these submodels are then presented and discussed.

\subsection{Data, Sampling and Estimation}

The demand and supply side submodels of CATLAS can be empirically calibrated using the U.S. Census of Population and Housing. In the Chicago application, the 1970 Census results were used because these were the most recent available. These data have been tabulated to a system of 4918 square zones of $1 / 2 \mathrm{mile}$ by $1 / 2 \mathrm{mile}$ covering the Chicago metropolitan area. Each zone of this grid system is called a quartersection. Transportation and travel characteristics data are availabie for the same zones and were obtained from the Chicago Area Transportation Study (CATS). The CATS data is aggregated to the traffic zone level which consists of one mile by one mile square zones in the city and larger zones in the suburbs. A 2 mile by 2 mile area centered on Madison and State Streets is taken to be the Central Business District or CBD. This area includes the "Loop", Chicago's traditional business center but is more than three times in area and contained $19 \%$ of all the jobs in the metropolitan region in 1970 .

To estimate the submodels of CATLAS, a random sample of 433 zones or nearly 9\% of the total number of zones was selected and used. Maximum likelihood for aggregated data is the technique used to estimate these models.

\subsection{Estimation of Demand Submodels}

The demand submodels discussed in section 2.2 and consisting of equations 
(14) - (18) have been estimated for two workplace categories $(h=1,2)$. The first workplace $(h=1)$ is the two mile by two mile CBD and the second $(h=2)$ is all: other employment dispersed throughout the rest of the Chicago SMSA (hereafter non-CBD). This dispersed "workplace" is represented by the average travel time and cost by each mode from each residential zone to all other employment zones excluding the CBD. This employment classification into CBD and non-CBD is appropriate only because CATLAS has been used to examine the impact of radial rail transit lines serving the CBD. These lines have most of their effects on CBD employment and these effects are quite insensitive to gross variations in dispersed non-CBD employment. Thus the above two-way classification goes a long way toward capturing the essential aspects of rail transit investment.

The actual modal choices of $C B D$ and non $-C B D$ commuters are shown in table 1. The CBD multinomial logit model is estimated with four modes of travel (auto, commuter rail, rapid transit and bus). The non-CBD model is estimated with two modes of travel (auto and bus). Al trips by other modes for CBD and non-CBD are treated as fixed in number for each residential zone and are added in as a constant to the left hand side of (1).

Table 2 lists the explanatory characteristics entered into the models, the value of each coefficient estimated and the t-statistic associated with that coefficient.

\subsection{Estimation of Occupancy and Stock Adjustment Submodels}

The occupancy, new housing construction and old housing demolition submodels discussed in section 2 have been estimated and the results are shown in table 3. Here PVR NEW is the present value of the revenue expected to accrue to a new dwelling and PVROL the present value of the revenue expected to accrue to an old dwelling over its remaining lifetime. Characteristics 4-16 are either 
dummy variables or zonal average measures proxying the cost sides of the occupancy, construction, and demolition decisions as explained in section 2. The occupancy and new construction submodels are estimated from the zonal data using maximum likelihood with the number of occupied units in each zone and the number of newly constructed units between 1969-1970 in each zone being known from the census. The number of dwellings demolished is not known by zone since it is not surveyed in the census. For this reason, the demolition submodel is estimated using a cruder method. The number of dwellings demolished in the entire Chicago SMSA in the 1960's is used.to determine a crude annual metropolitan demolition rate. The model coefficients are then adjusted by trial and error to achieve a good fit to this aggregate demolition rate. For this reason standard errors (and t-statistics) cannot be computed for the demolition submodel.

\section{SIMULATIONS AND POLICY IMPLICATIONS}

In this section we present and discuss the simulation results obtained from the application of CATLAS to evaluate rapid transit projects proposed for the Southwest side of chicago. The results are rich in policy implications regarding transit financing and these are discussed in this section.

\subsection{Simulation Data and Assumptions}

For the purposes of performing equilibrium simulations with CATLAS the zones of the Chicago SMSA are aggregated to the 1690 traffic zones as shown in figure 1. The same figure also shows the boundary of the Southwest corridor expected to be impacted in a major way by the proposed transit projects. Figure 2 shows the alignment of existing commuter rail and rapid transit lines within the corridor and also the alignment of three alternative proposed rail lines: the Archer Avenue subway, the Gulf Mobile and Ohio right-of-way project and the 
Indiana Harbor Belt right-of-way project. The last two projects would be built on the rights-of way of freight railroads known by the same name.

Introduction of any one of these rail projects would change the zone-to-CBD transit travel times and costs of the zones within the Southwest corridor. To compute these new times and costs we need to take into account the changed costs of access to the new rapid transit stations. This was done by adopting an access mode choice model developed for the Chicago area by Sajovec and Tahir (1976). This model allows access to stations by walking, bus and automobile. The access costs and times computed from this model are added to the station-toCBD line haul times and the minimum time route is then computed for each zone. The costs and times of these zones are then entered into the demand model for the CBD, replacing the times and costs existing prior to the new project.

In the policy simulations to be reported, it is assumed that the new transit projects will influence the decisions of CBD commuters only. Since in reality the transit project will draw trips from other employment locations as well, its impact on housing values and land use will be larger than that predicted in these simulations. In fact these results should be taken as lower bounds of the impact of the transit lines.

Tables 4 and 5 show the 1970 aggregate descriptive data for the Chicago SMSA and Southwest corridor respectively. The construction costs of the three rail projects were computed using detailed project descriptions and the unit costs from Permut and Zimring (1975) and Krueger et a 1. (1980). In 1970 dollars, the GM\&O project would cost $\$ 120.4$ million, the Archer subway $\$ 235.5$ million ad the IHB project $\$ 249.1$ million respectively.

\subsection{Simulation Results and Transit Finance Implications}

Two kinds of simulations are performed using CATLAS. The first of these is a static simulation in which the housing stock in each zone is held fixed at its 
1970 level. This simply means that the housing stock adjustment submodels are removed from the recursive structure and the model deals ony with the allocation of households to dwellings by employing the demand and occupancy submodels. The second type of simulation uses the full recursive structure to simulate changes in the housing stock over time. The static simulations provide sufficient insight into certain basic results. Thus the results of these simulations will be presented first.

\subsubsection{Static Simulations}

Table 6 shows the effects of the three projects on aggregate rent changes, mode patronage (or demand) changes for CBD and non-CBD commuters. These can be looked at for the entire SMSA and for the Southwest corridor and by city and suburb in each case. The projects have the following effects: they increase the attractiveness or utility of central city zones by reducing transit travel times and costs and by extending such service to where it was not previously available. The effect is to attract some households to relocate from the suburbs to the city thus raising city rents while reducing suburban rents. Aggregate metropolitan rents are reduced because the movement of households is from the higher rent suburbs to the lower rent central cities. When we look into the Southwest corridor we see that aggregate rents increase in both the city and suburban parts of the corridor. A zone by zone view of these rent changes are shown in figures 3,4 and 5 for the three projects. Rent changes outside the Southwest corridor are extremely small in magnitude (amounting to several dollars per dwelling annually at most) and can be ignored from a taxation viewpoint. If the special assessment district is defined to coincide with the boundary of the corridor and an incremental special assessment tax is implemented within this corridor taxing away the increases from the dwellings which appreciate in value and giving rebates to dwellings which decline in 
value, the incremental revenue collected in this way amounts to $\$ 6.4-\$ 8.2$ million annually.

How big is the tax burden of such a special assessment on the housing owners in the corridor? The maximum zonal average rent increases are $\$ 247, \$ 235$ and $\$ 235$ per year from figures $3-5$ respectively, or about $\$ 20$ per month. In the vast majority of zones, rent increases are a lot lower. The average rent increase per dwelling in the corridor is just under $\$ 25$ per year for the GM\&0 project. These figures show that the tax burden on the average housing owner is small and thus a special assessment policy is not likely to encounter major political opposition if it is carefully explained to the public and if the potential for rent increases is carefully documented. We also see that where rents decrease the decreases are negligible and thus if no rebates are given to such housing owners there will be no political opposition.

The next question of policy interest is "what percentage of the capital cost of these transit lines can be captured via the incremental tax method?" The answer depends crucially on what interest rate is used in discounting the annual tax revenues. Moody's Bond Survey Record gave a Ba rating to the Chicago Transit Authority in 1970. Bonds issued in 1970 with a Ba rating generally paid 10\% interest. Using this interest rate the project capital costs are annualized over a 35-year horizon and the annual operating costs are computed using a procedure of the Chicago Transit Authority (1980).

\subsubsection{Dynamic Simulations}

The purpose of the dynamic simulations is to determine whether the policy implications of the static simulations hold up or are substantially altered by the introduction of the stock adjustment submodels. The results obtained from the dynamic simulations depend crucially on what assumptions are made regarding the increase of employment (and population) for the Chicago SMSA. The results 
are also sensitive to year-by-year changes in the input variables.

Because the time path of the input variables are uncertain, one approach to dynamic simulation is to keep these constant over time. If this is done, then the housing stock adjustment submodels will forecast the redistribution and ageing-renewal of a fixed total housing stock.

The following assumptions were employed:

1) The aggregate number of households and commuters is determined within the model by assuming that the aggregate housing vacancy rate will stay at the 1970 level and the number of households will adjust year by year according to changes in the housing stock.

2) All other input variables remain at their 1970 levels.

3) The distribution of jobs between the CBD and the non-CBD locations maintain their 1970 proportions.

We believe these assumptions to be the most prudent given our limitations in forecasting the future paths of the input variables.

Given the above assumptions, we performed a twenty-year simulation (i.e. from 1970-1990) without introducing any changes in the transportation system (this is called a baseline simulation or base run) and a twenty-year simulation in which the GM\&O project is introduced (this is called a policy simulation or policy run).

The results of these baseline and policy simulations are shown in tables 710 for both the entire SMSA and for the Southwest corridor.

The aggregate rent changes and other fluctuations are caused by two factors. The first is the change in total housing stock and the second the housing redistribution among the zones. For the SMSA results (table 7) the aggregate rent changes are larger than the housing stock changes in the first several years because the new housing constructed in the suburbs is more 
valuable and there are fewer housing units remaining in the city due to demolitions. Following the construction of new housing units, the available vacant land is reduced; thus fewer housing units can be constructed. In the meantime, as the old housing units age, more of them will be demolished. Beginning with the ninth year, the housing stock decreases. When the pace of population increase starts to slow down, owners find that it is more difficult to rent or sell dwellings and demand lower rents. This explains the decrease of aggregate rents in the later years. The results for the southwest corridor (table 8 ) are similar to the SMSA results, but because the average housing age is higher and the available vacant land is less than in the SMSA, the housing stock within the corridor begins to decrease from the first year and so do the aggregate rents.

The results of the GM\&O policy simulation are shown in tables 9 and 10 which document the difference between the policy simulation and the corresponding baseline simulation. The most notable result is that the transit project has a very small net influence on the housing stock changes. In other respects the results are similar to the static simulations.

Two other policies were also simulated. In one of these the GM\&O project is introduced and it is assumed that CBD parking fees double. In the second, it is assumed that the price of gasoline doubles. The estimated cost and cost recovery ratios are shown in table 11 . In obtaining these figures, it was assumed that the incremental special assessment tax would be levied on vacant land as well as on housing units. It can be seen that the aggregate land value change in the Southwest corridor due to the project is quite small because less than $8 \%$ of the available vacant land is within the corridor. The cost recovery ratios are quite close to those of the static simulations. 


\subsection{Caveats and Conclusions}

Any large scale simulation analysis is not an exact science and is subject to numerous sources of error and bias. Most of these are inherent in the data and in the mathematical form and assumptions of the analysis. Such sources of error and bias are unavoidable. The best one can do is to gain an intuition for the magnitudes of these errors and biases by performing extensive sensitivity testing on the various aspects of the analysis system including the estimated coefficients and elasticities. Such sensitivity tests were performed and have been reported in Anas (1982) and Duann (1982). Despite the fact that results can change substantially if some coefficients are doubled or tripled or if some data has not been accurately measured, little reason exists to doubt the basic conclusions. In the final analysis we remain confident in the general approach and method used because we cannot identify any systematic sources of bias that weaken our conclusions.

There are several strong qualitative arguments that the total impact of transit on property values is stronger than that estimated in our application. This means that our quantitative results may be better viewed as lower bounds. We know, for example, that if CATLAS is extended to deal with nonwork trips as well as with work trips, then the impacts of transit on housing values will be higher because travel cost and time savings in nonwork travel will be capitalized into housing values. Similarly, if the non-CBD workplaces are identified by exact location rather than lumped together into one category, there will be additional gains in work travel translated into housing price increases. Finally, if we include commercial and industrial properties into the analysis, we will find that these too, and especially commercial floor space, appreciates in value substantially.

Another caveat is that the value capture cost recovery ratio of bus systems is surely higher than that for rail. This does not necessarily occur because 
bus systems have a stronger impact on housing values, but because the rolling stock cost of bus systems is much lower than the construction and rolling stock cost of rail systems. Thus, it should not be surprising if a similar analysis were to yield a cost recovery ratio for bus systems of $100 \%$ or higher. Such a result is not very useful, however, because it is the finance of rapid rail systems, and particularly of their capital cost, that poses the major challenge in the years ahead. It is clear that these costs cannot be covered out of the farebox if reasonable levels of ridership are to be maintained. Incremental special assessment taxes on real estate appear to be a promising way of financing a significant part of the capital costs of rail systems. 


\section{REFERENCES}

Adkins, W.G., 1959, Effect of the Dallas Central Expressway on Land Values and Land Use, Texas Transportation Institute.

Alonso, W., 1964, "Location and Land Use", Harvard University Press, Cambridge, Mass.

Anas, A., 1981, "The Estimation of Multinomial Logit Models of Joint Location and Travel Mode Choice from Aggregated Data", J. Regional Sci., 21(2), p.223-242.

Anas, A., 1982, Residential Location Markets and Urban Transportation, Academic Press.

Arnott, R.J. and Stiglitz, J.E., 1981, "Aggregate Land Rents and Aggregate Transport Cost", The Economic Journal, 91, pp. 331-347.

Ashley, R.N., 1965, "Interchange Development Along 180 Miles of I-94", Highway Research Record 96, Highway Research Board.

Beckmann, M.J., 1969, "On the Distribution of Rent and Residential Density", J. Econ. Theory.

Boyce, D.E. and Allen, B., 1973, "Impact of Rapid Transit on Suburban Residential Property Values and Land Development", Department of Regional Science, University of Pennsylvania, Philadelphia, Pa.

Chicago Transit Authority, 1980, "Estimates of Heavy Rail Operating Costs: Southwest Transit Study", General Operations Division, Operations Planning Department.

Davis, J.L., 1965, The Elevated System and the Growth of Northern Chicago, Northwestern University, Studies in Geography No. 10.

deleeuw, F. and Struyk, R.M., 1975, The Web of Urban Housing: Analyzing Policy with a Simulation Model, The Urban Institute, Washington, D.C.

Dewees, D.N., 1976, The Effect of a Subway on Residential Property Values in Toronto; J. Urban Econom., 3(4), 357-369.

Domencich, T., and McFadden, D., 1975, "Urban Travel Demand: A Behavioral Analysis", North-Holland Publ., Amsterdam.

Duann, L.S., 1982, "A Dynamic Simulation Model for Residential Location, Travel Mode Choice and Residential Land Development", PhD Dissertation, Department of Civil Engineering, Northwestern University.

Golden, J.S., 1968, "Land Values in Chicago: Before and After Expressway Construction". The Chicago Area Transportation Study.

Ingram, G., Kain, J., and Ginn, J.R., et al., 1972, "The National Bureau of Economic Research, Detroit Prototype, Urban Simulation Model", Columbia University Press, New York, amd the NBER. 
Krueger, C., Heramb, C., Kunze, B., and Gallery, M., 1980, Southwest Transit

Study, Phase I Report: Preliminary Alternatives Analysis. City of Chicago, Department of Public Works, Bureau of Transportation Planning and Programming.

Lemly, J.H., 1959, "Changes in Land Use and Value Along Atlanta's Expressways", Highway and Economic Development, Highway Research Board Bulletin 277.

Lerman, S.R., 1977, Location, Housing and Automobile Ownership and Mode to Work: A Joint Choice Model, Transportation Res. Record, (610).

McFadden, D., 1973, "Conditional Logit Analysis and Qualitative Choice Behavior", in "Frontiers in Econometrics", Academic Press, N.Y.

McFadden, D., 1978, Modelling the Choice of Residential Location. In "Spatial Interaction Theory and Planning Models" (A. Karlqvist et al., eds.) NorthHolland Publishing, Amsterdam.

Mohring, H., and Harwitz, M., 1962, "Highway Benefits: An Analytical Framework", Northwestern University Press, Evanston, Illinois.

Mudge, R., 1972, The Impact of Transportation Savings on Suburban Residential Property Values, PhD Dissertation, University of Pennsylvania, Philadelphia.

Muth, R.F., 1969, "Cities and Housing", University of Chicago Press, Chicago.

Permut, H. and M. Zimring, 1975, "Capital and Operating Costs for the Expansion of the Chicago Rapid Transit System", Technical Report, Regional Transportation Authority, Chicago, Illinois.

Quigley, J., 1976, Housing Demand in the Short Run: An Analysis of Polytomous Choice, in "Explorations in Economic Research", (S.D. Winter, ed.), Vol. 3 , No, 1, pp. 76-102.

Sajovec, J. and Tahir, N., 1976, "Development of Disaggregate Behavioral Mode Choice Models for Feeder Bus Access to Transit Stations", M.S. Thesis, Northwestern University, Evanston.

Sheiton, J.P., "The Cost of Renting Versus Owning a Home", Land Econ., February 1968, pp. 59-72.

Szemg;er. E.H., 1930; Land Values in New York in Relation to Transit Facilities, AMS Press.

Wheaton, W.C., 1974, "A Comparative Static Analysis of Urban Spatial Structure", Journal of Economic Theory.

Wootan and. Haning, 1960; Changes in Land Values, Land Use and Business Activity -Along a Section of the Interstate Highway System in Austin, Texas, Texas Transportation Institute. 


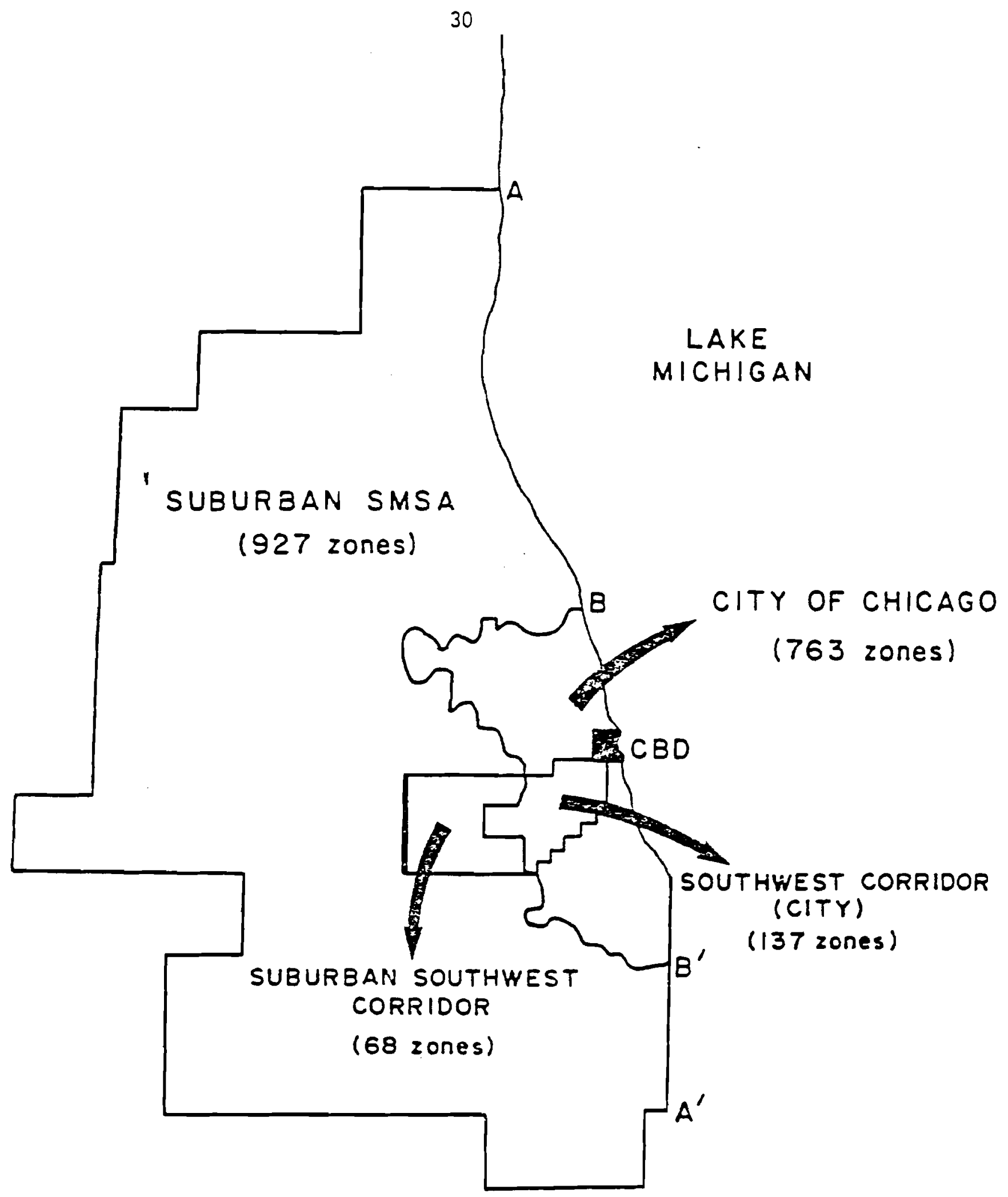

Figure 1: The 1590 Zone System Used for Policy Simulations with CATLAS. 
0
0
0

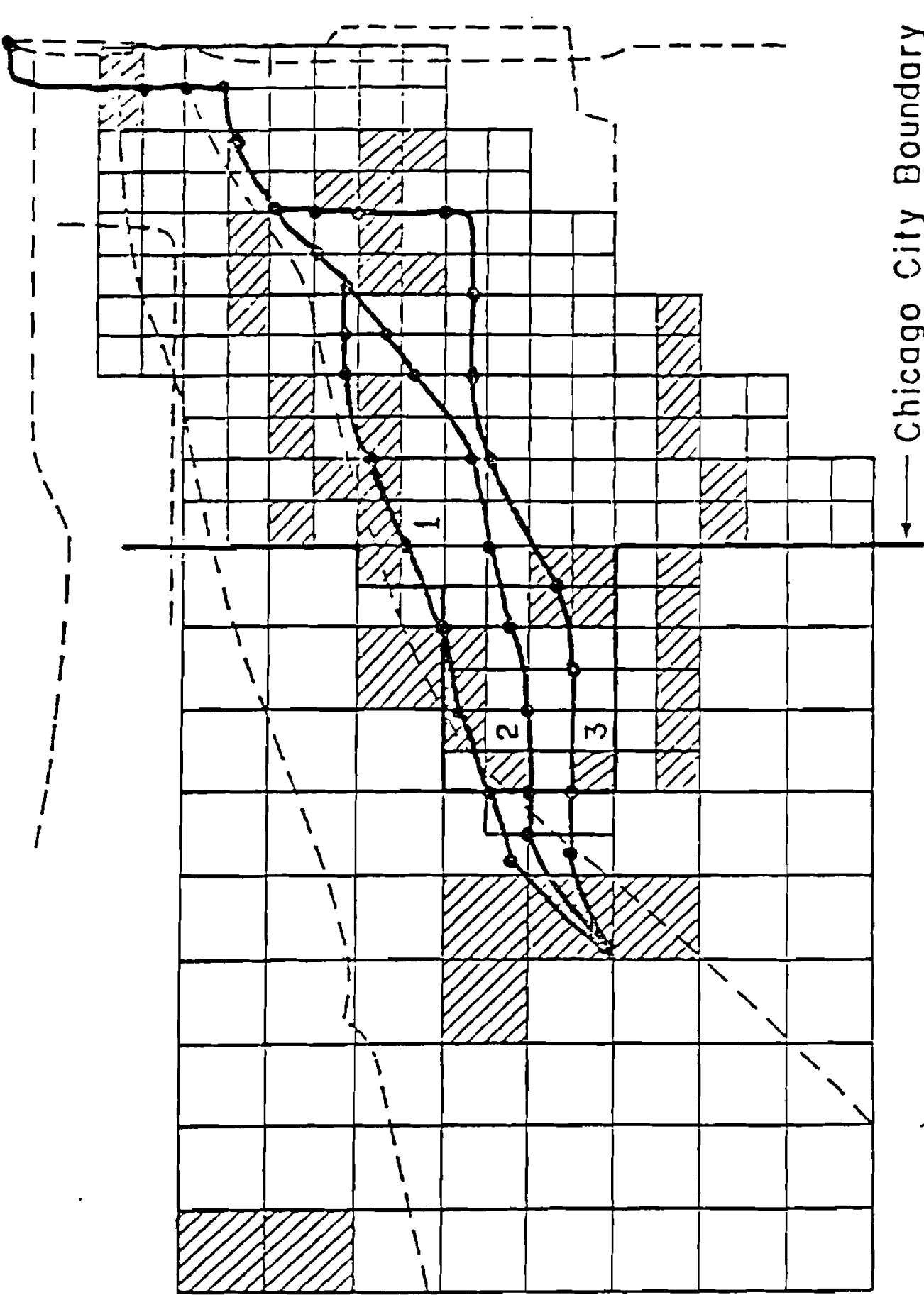

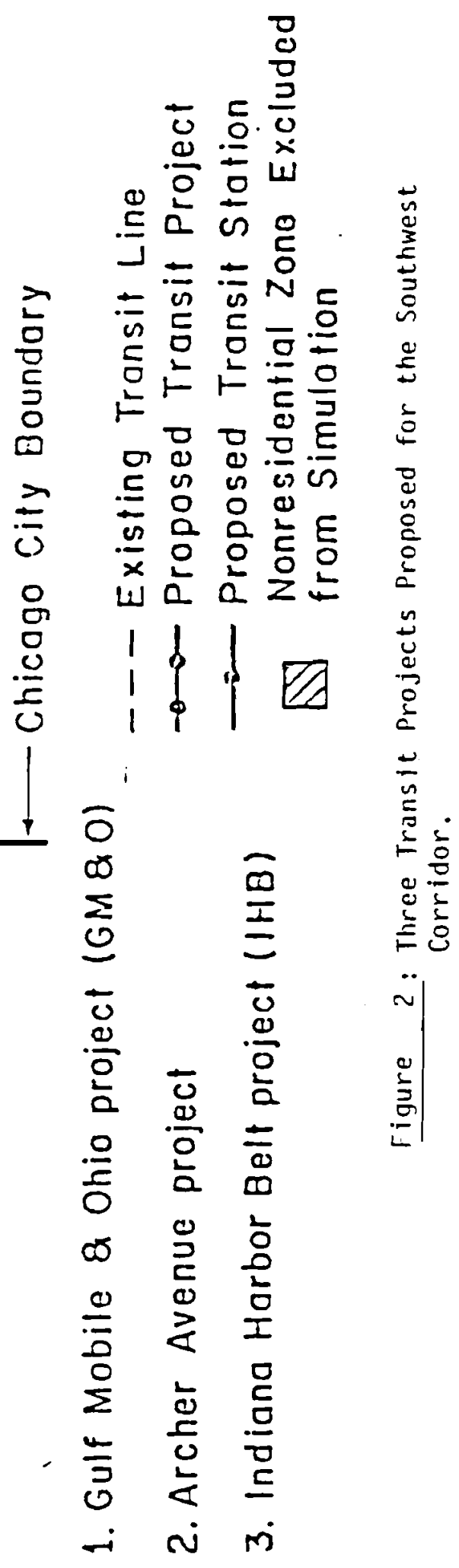




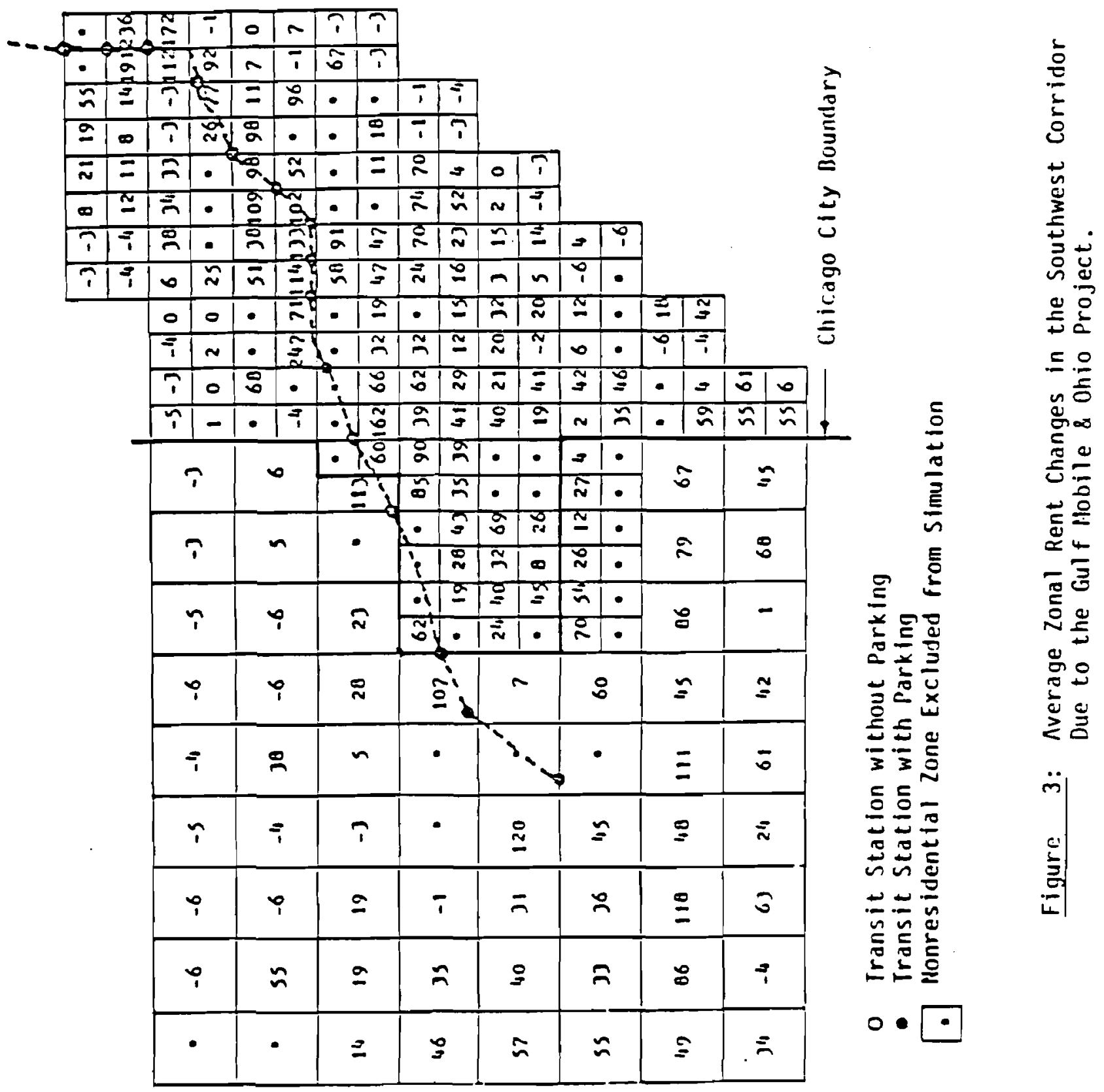




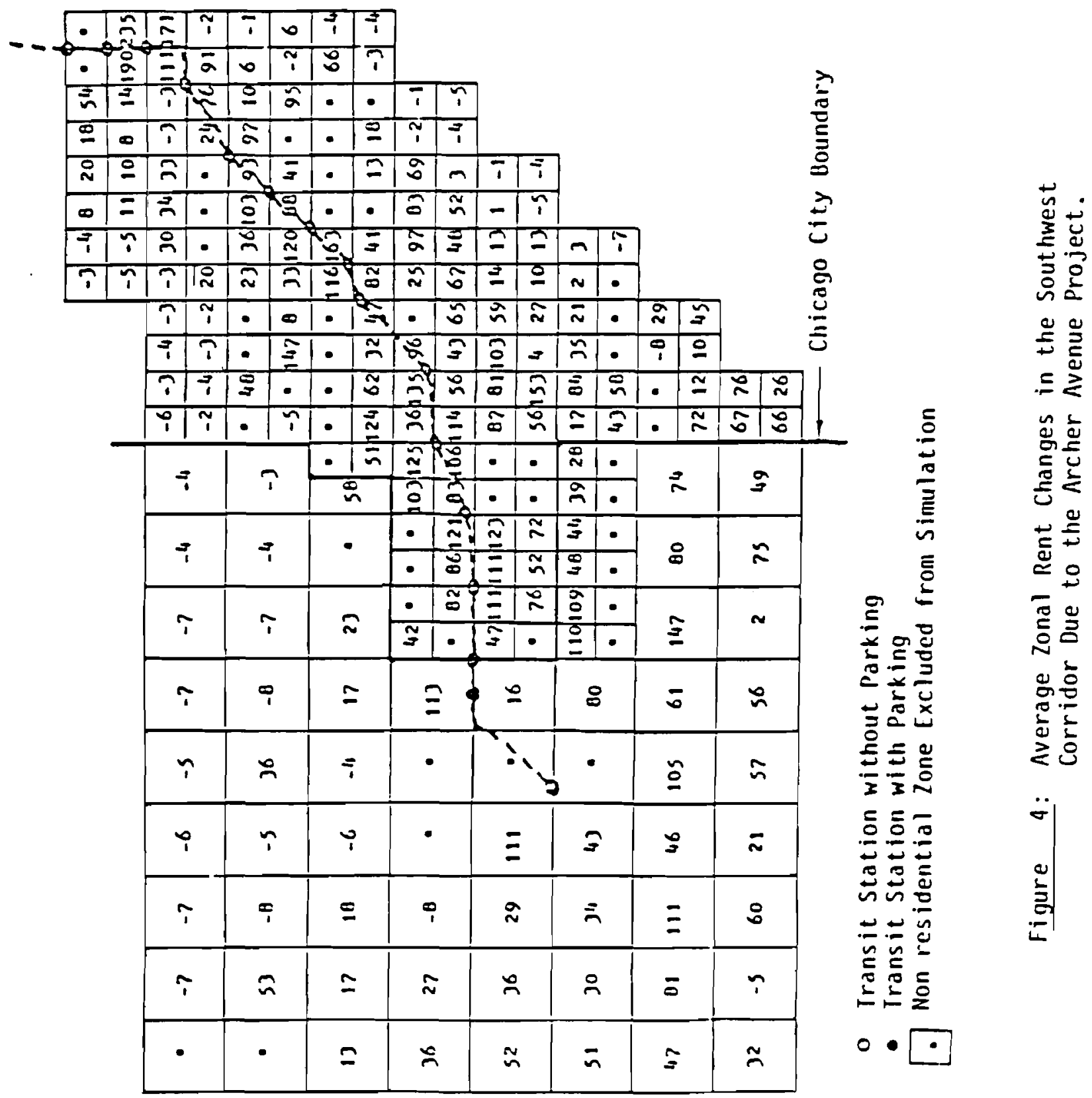




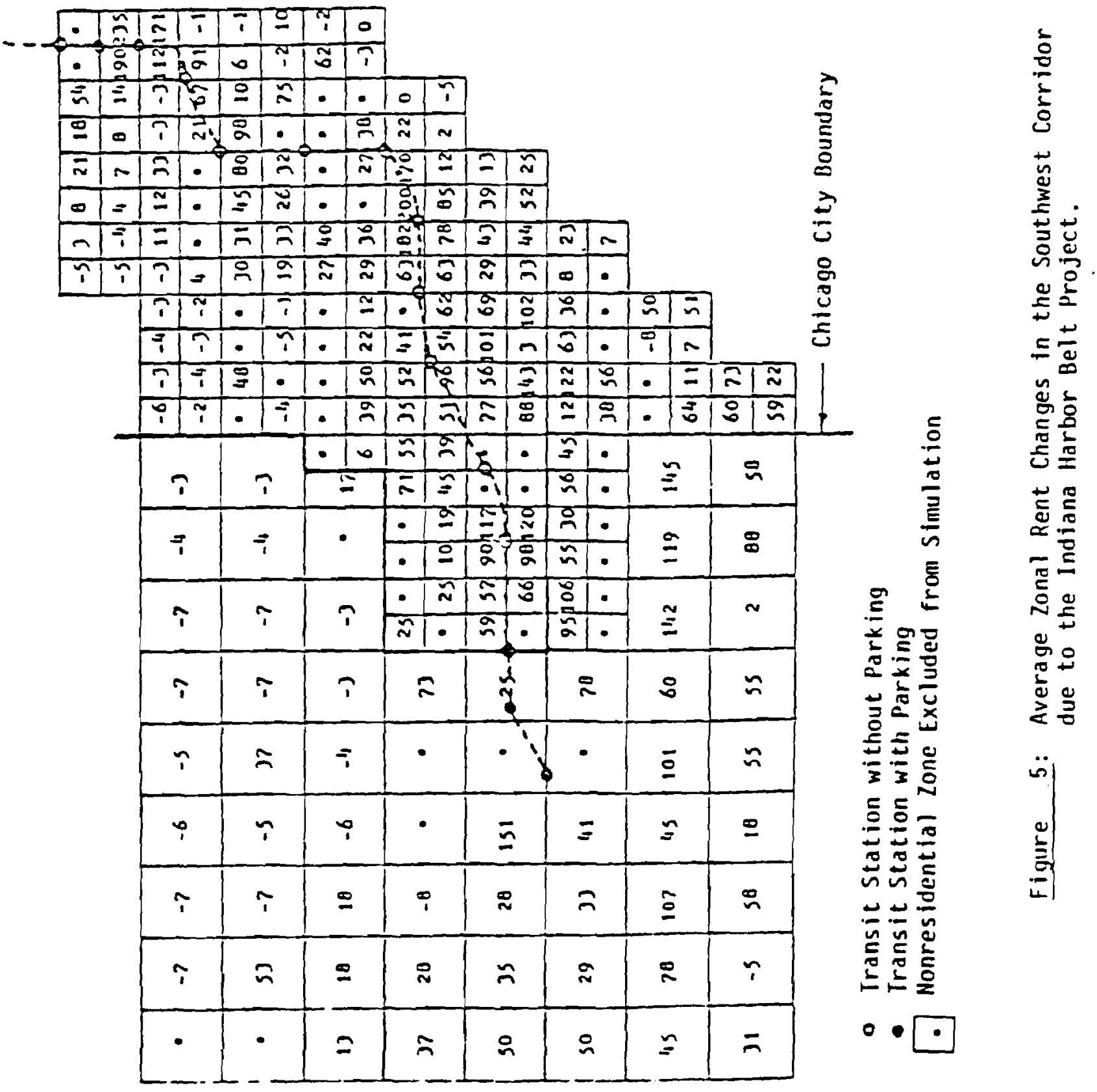


Location of Workplace

Travel Modes

Auto driver

Auto passenger

Commuter rail

Rapid transit

Bus

Other

Total
Inside CBD

$129,995(29 \%)$

$28,251(6 \%)$

$77,908(17 \%)$

$83,092(18 \%)$

$108,400(24 \%)$

$26,050(6 \%)$

$453,696(19 \%)$
Outside CBD Mode Totals

$\begin{array}{rr}1,184,372(61 \%) & 1,314,367(55 \%) \\ 230,598(12 \%) & 258,849(11 \%) \\ 26,665(1 \%) & 104,573(4 \%) \\ 38,849(2 \%) & 121,941(5 \%) \\ 232,109(12 \%) & 340,509(14 \%) \\ 231,373(12 \%) & 257,423(11 \%)\end{array}$

$1,943,966(81 \%)$

$2,397,662$ 
1. Housing supply

2. Inclusive vaiue

3. Commuter rail (CR) dumy

4. Rapid transit (RT) dummy

5. Bus dummy

6. Log (Travel time)

7. Log (Travel cost + rent)

8. Bus miles/square mile

9. RT stations within 0-0.5 miles

10. RT stations within 0.5-1 miles

11. RT stations within 1-2 miles

12. CR stations within $0-1$ miles

13. Log (Housing age)

14. Log (Zone income)

15. $\log$ (Distance to the CBD)

16. Log (Angle from Lake Michigan)

17. D] (0-10 miles)

18. $02(10-20$ miles $)$

19. 03 (> 25 miles)

20. Log (Rooms) $u_{c}=1.000$

$a_{:}=0.723$ $(30.7)$

$\gamma_{z}=-.846$ (23.0)

$a_{3}=-1.701$ (39.0)

$\alpha_{11}=-0.636$ (12.3)

$x_{5}=-2.392$ $(55.5)$

$a_{6}=-1.488$ $(12.4)$

$\therefore 7=0.020$ $\left(54 . r^{\prime}\right)$

$a_{\varepsilon}=0.294$ (20.9)

$a_{g}=0.134$ (9.9)

$a_{10}=0.246$ (23.2)

$a_{11}=0.349$

$a_{12}=-0.188$ (14.0)

$a_{13}=1.015$ (53.2)

$\alpha_{1 L}=0.447$ (18.4)

$\therefore 5=0.001$ * $(0.08)$

(a) $f=0.490$ $(19.6)$

$a_{17}=0.122$ (6.0)

$u_{10}=-0.591$ (20.6)
1.000<smiles>[CH]1C[CH]C1</smiles>

0.955

(15.3)

$-2.627$

(175.0)

$-0.910$

(25.7)

$-5.461$

$(42.6)$

0.017

(70.5)

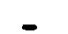

$-0.09 .7$

(14.5)

$-0.117$

(8.4)

0.426

(47.9)

$-0.206$

(23.0)

0.287

(20.2)

0.296

(29.9)

0.132

(12.3)

1.194

(62.0)

0.420

0.828

TABLE 2: Estimated coeficients and t-statistics of the CBD and non-CBD multinomial logit demand functions. 
Explanatory

Characteristics

1. Annual rent

2. $P V R_{N E W}$

3. PVR OLD

4. Rental dummy

5. Build dumy

6. Don't demolish dummy

7. City location durmy

8. Distance to CBD

9. Angle

10. Rooms

11. Housing age

12. $\log$ (Housing age)

13. \% Black Households

14. \% Developed land

15. : Single family housing

16. Zonal income
Estimated Coefficients Occupancy Hew Construction Demolition ( $\left.\bar{\prime}^{\prime} \mathrm{s}\right)$ ( $\left.\gamma^{\prime} s\right)$ $(s ' s)$

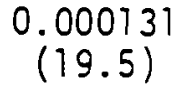

0.000131

(19.5)

\begin{tabular}{|c|c|c|}
\hline- & $\begin{array}{c}0.00001018 \\
(12.95)\end{array}$ & - \\
\hline- & - & $\begin{array}{c}0.00002135 \\
(-)\end{array}$ \\
\hline $\begin{array}{l}-0.679 \\
(17.2)\end{array}$ & - & - \\
\hline - & $\begin{array}{l}2.214 \\
(62.88)\end{array}$ & - \\
\hline - & - & $\begin{array}{c}4.595 \\
(-)\end{array}$ \\
\hline - & $\begin{array}{r}-0.6162 \\
(34.35)\end{array}$ & - \\
\hline- & $\begin{array}{r}-0.09660 \\
(137.2)\end{array}$ & $\begin{array}{c}-0.03853 \\
(-)\end{array}$ \\
\hline $\begin{array}{r}0.00131 \\
(19.9)\end{array}$ & $\begin{array}{r}-0.003345 \\
(35.51)\end{array}$ & $\begin{array}{c}-0.001892 \\
(-)\end{array}$ \\
\hline- & - & $\begin{array}{r}-0.1135 \\
(-)\end{array}$ \\
\hline- & - & $\begin{array}{r}-0.0146 \\
(-)\end{array}$ \\
\hline $\begin{array}{l}0.516 \\
(53.0)\end{array}$ & - & - \\
\hline $\begin{array}{r}-0.00347 \\
(32.2)\end{array}$ & $\begin{array}{r}-0.007379 \\
(30.94)\end{array}$ & $\begin{array}{c}-0.002736 \\
(-)\end{array}$ \\
\hline $\begin{array}{c}0.0119 \\
(61.1)\end{array}$ & - & - \\
\hline $\begin{array}{l}0.0181 \\
(119.1)\end{array}$ & $\begin{array}{c}0.0119 \\
(61.1)\end{array}$ & $\begin{array}{c}0.011137 \\
(-)\end{array}$ \\
\hline- & $\begin{array}{c}0.00003756 \\
(21.7)\end{array}$ & $\begin{array}{c}0.00010326 \\
(-)\end{array}$ \\
\hline
\end{tabular}

0.981

0.835

Table 3: Estimated coefficients and t-statistics of the occupancy, new housing construction and old housing demolition submodels. 


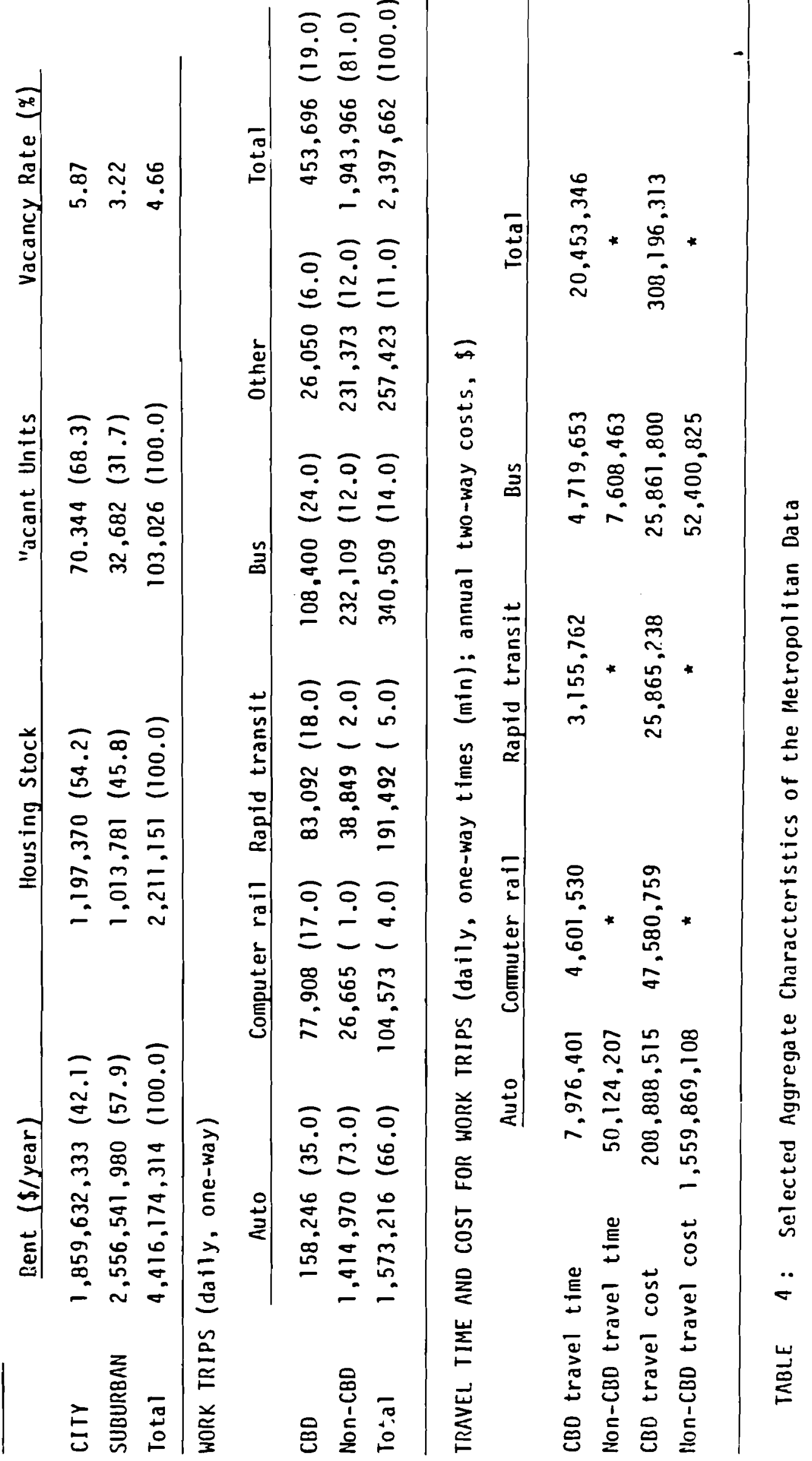




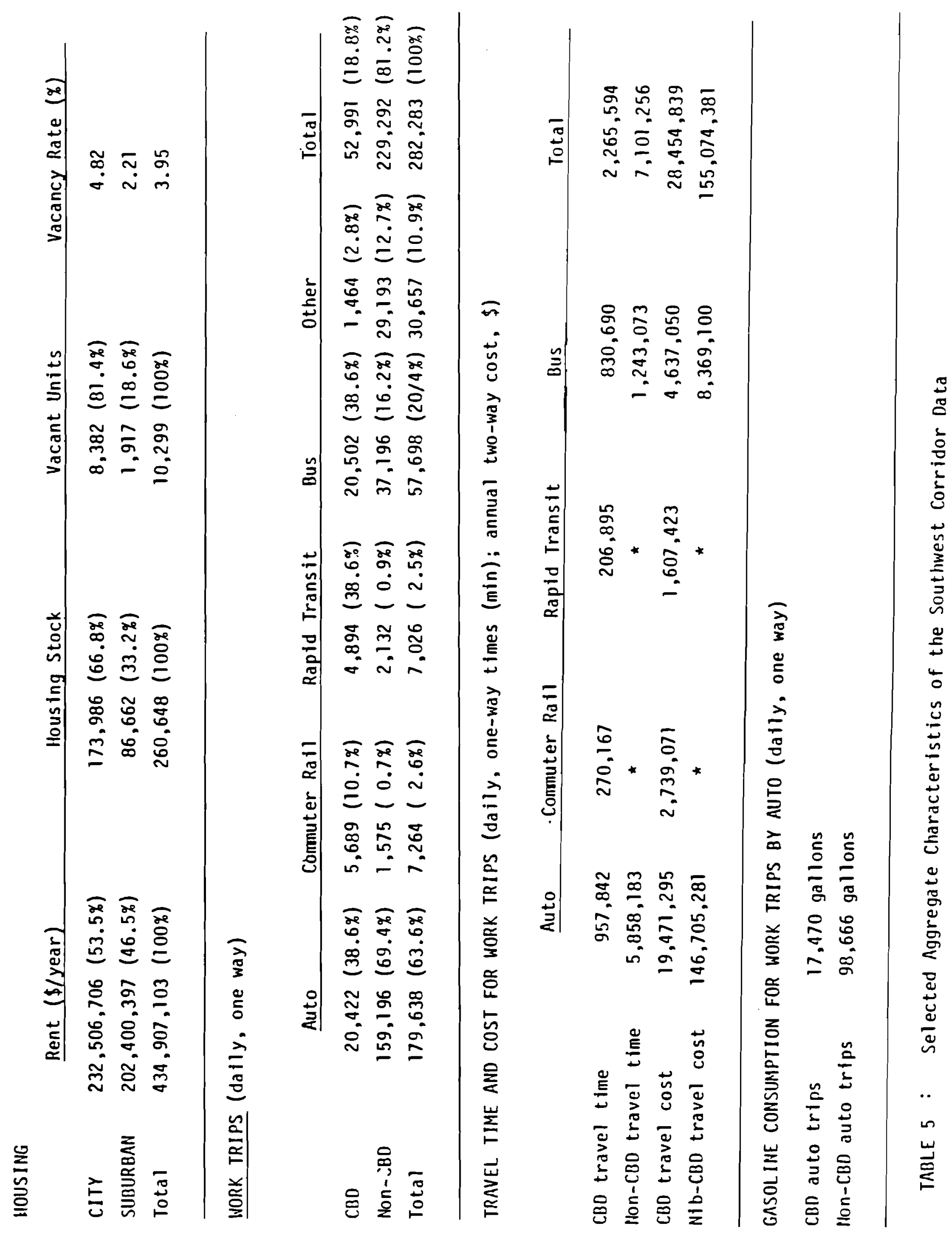



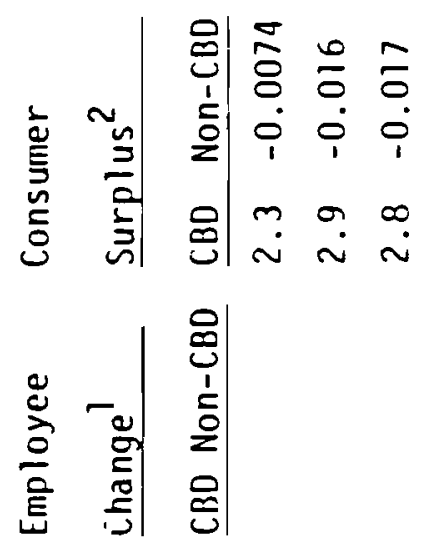

g

$\frac{0}{5} \tilde{ก}$

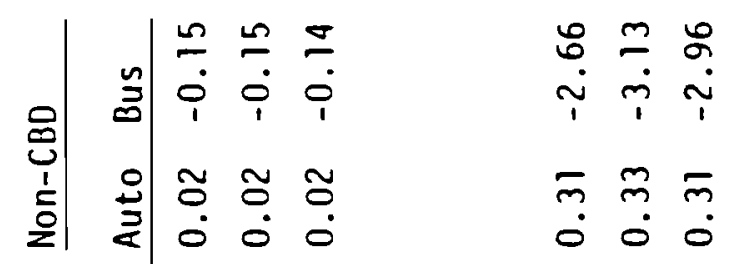

言

음

$\begin{array}{lll}0 & 0 \\ 0 & 0 & 0 \\ 1 & 0 & 0\end{array}$

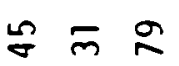

ஸ்

$\approx$ б.

$\because \underset{1}{\sim}$

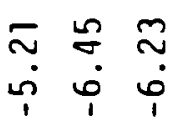

$\stackrel{0}{2}$

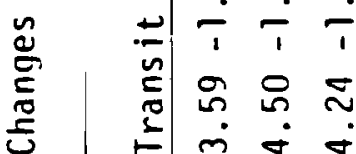

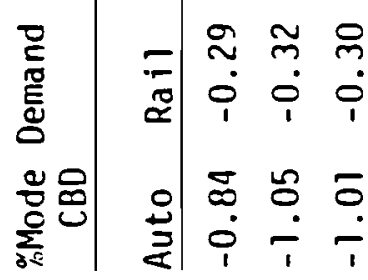

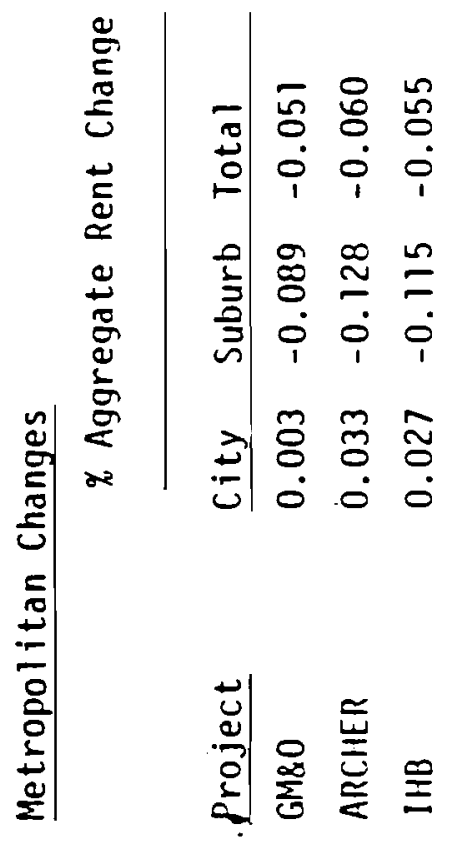

$\stackrel{\infty}{\infty} \underset{-\infty}{-}$

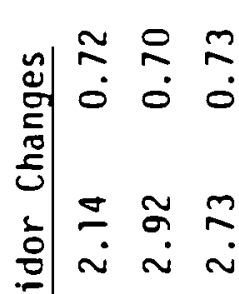




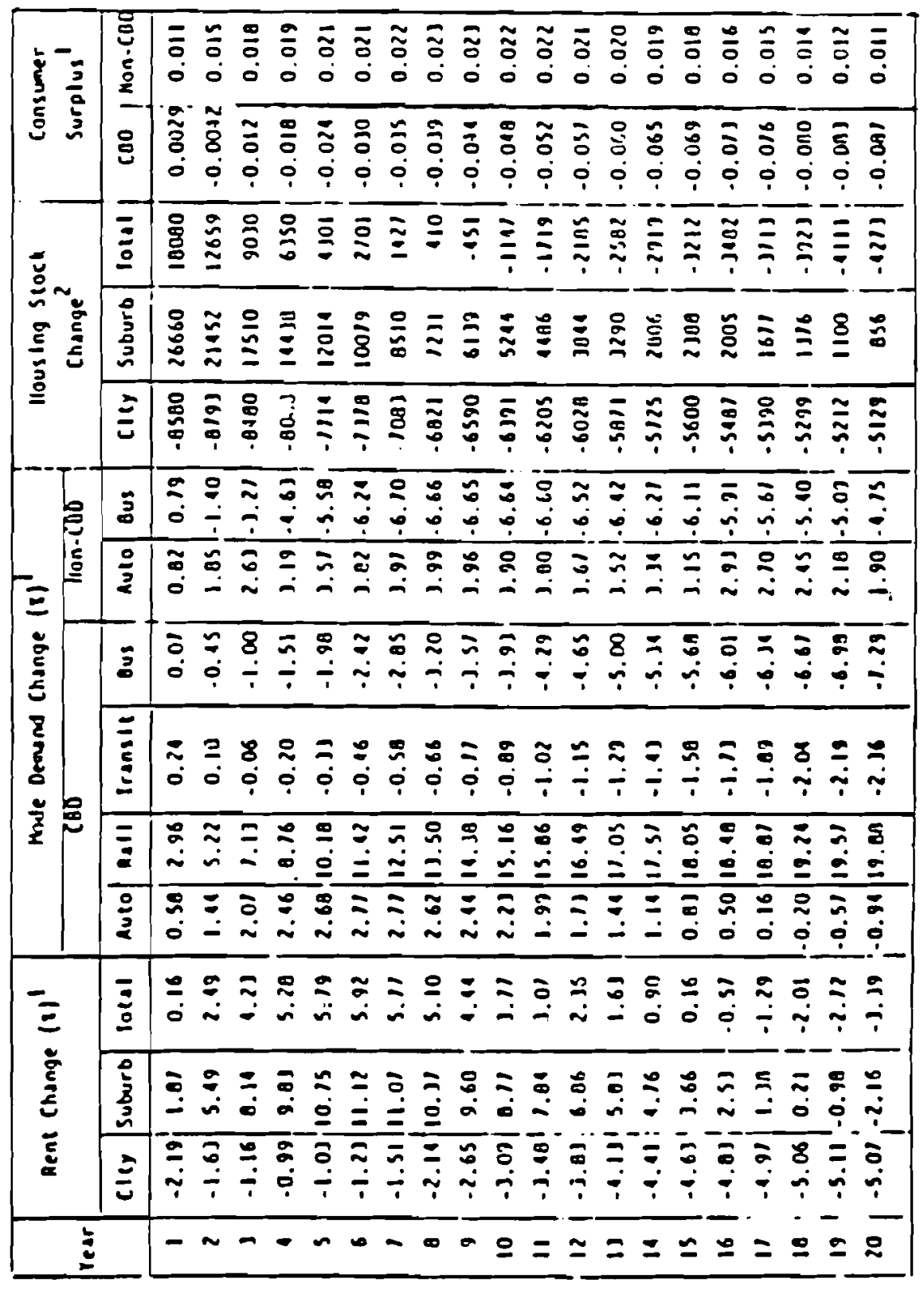

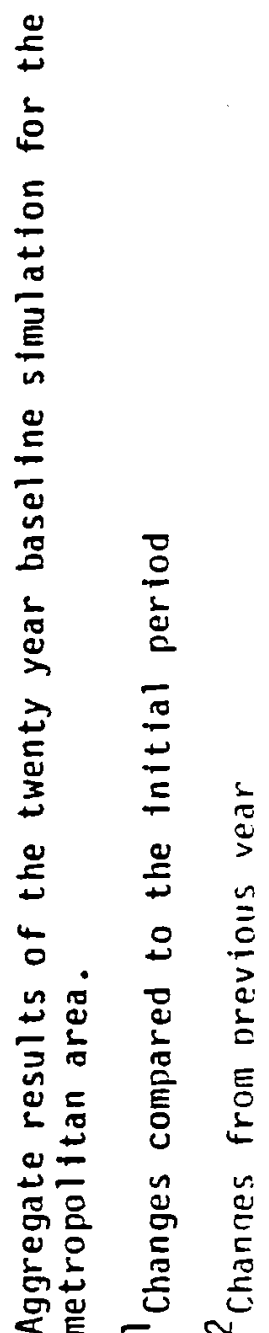

$\ddot{r}$
$\stackrel{0}{E}$ 


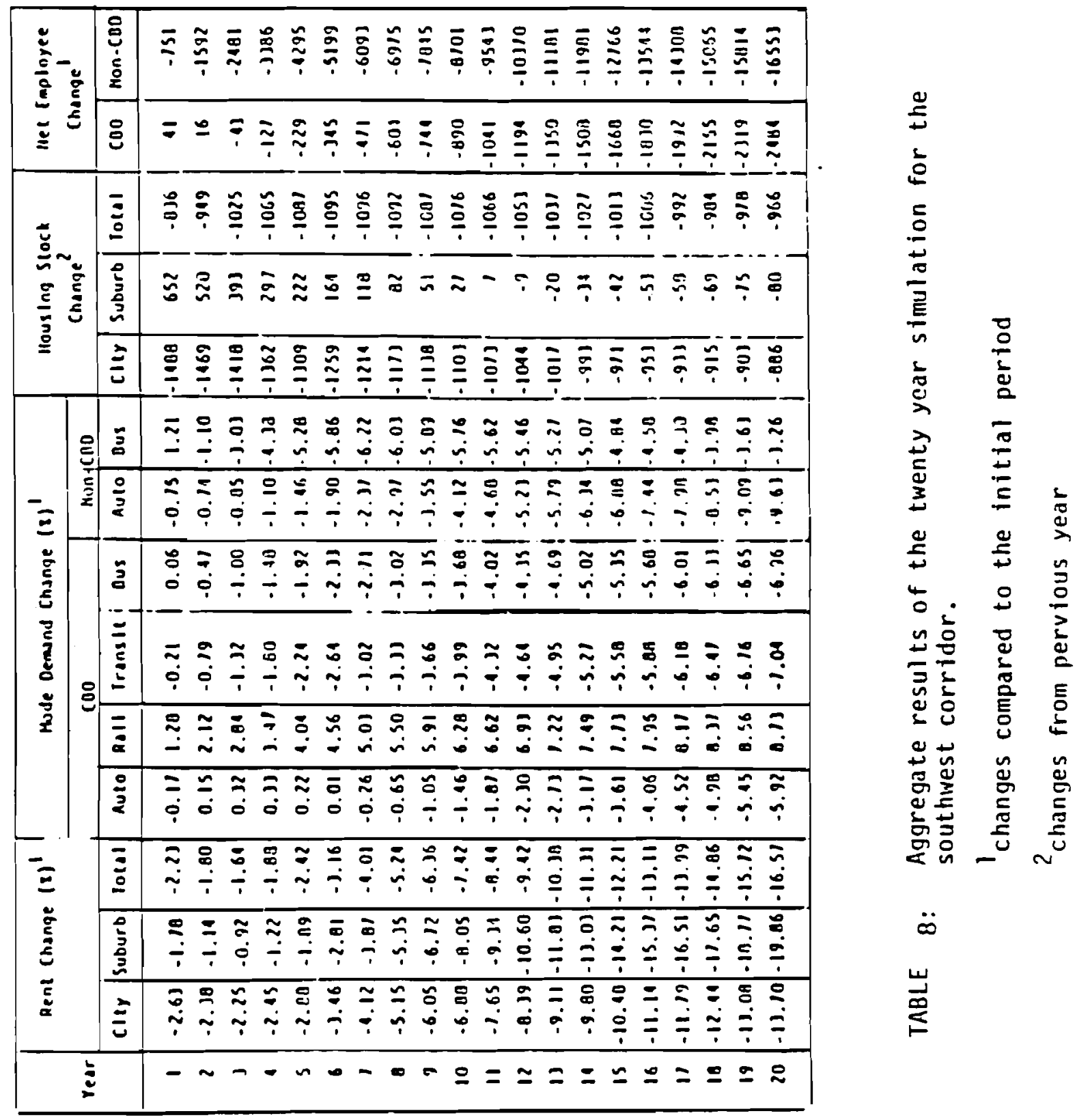




\begin{tabular}{|c|c|c|}
\hline \multirow{2}{*}{$\frac{5}{\vdots} \frac{\vdots}{\vdots}$} & 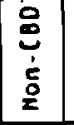 & 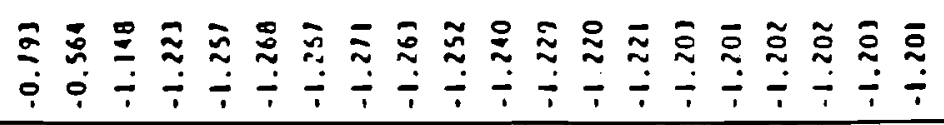 \\
\hline & $\Xi$ & 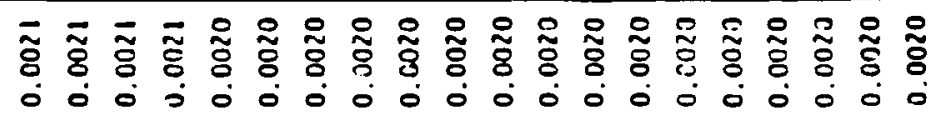 \\
\hline \multirow{3}{*}{ 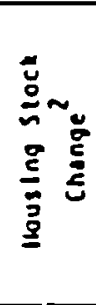 } & 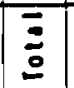 & $0 \div-n--\infty 0_{n} n n-m n-n$. \\
\hline & 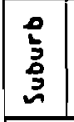 & $0 \sim \tilde{\varphi}, 0 \sim \sim \sim \sim$ \\
\hline & $\Xi$ & $0 m n n n n+.+m m n \sim-0---0-$ \\
\hline \multirow{6}{*}{ 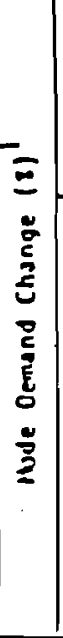 } & 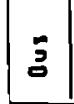 & 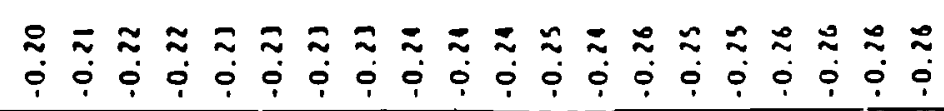 \\
\hline & $\frac{1}{2}$ & 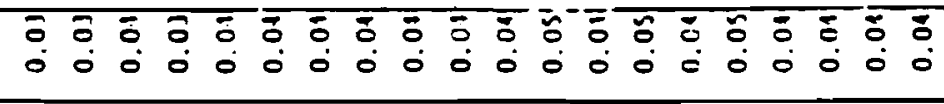 \\
\hline & $\bar{\Xi}$ & 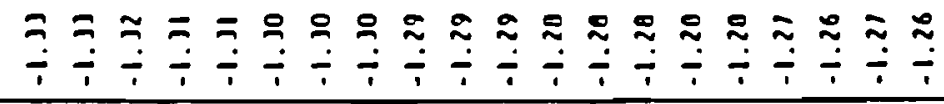 \\
\hline & 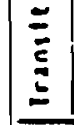 & 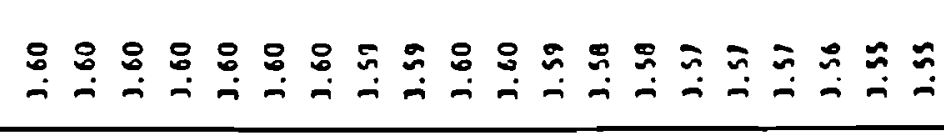 \\
\hline & $\overline{\bar{\alpha}}$ & 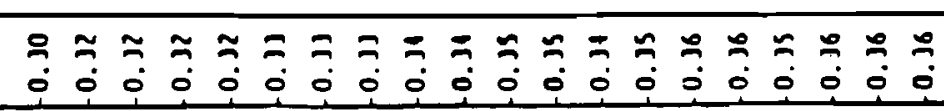 \\
\hline & ב⿱⺈ & 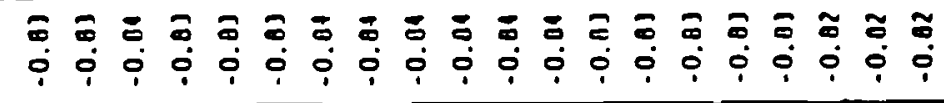 \\
\hline \multirow[t]{3}{*}{$\Xi$} & $\bar{\vdots}$ & 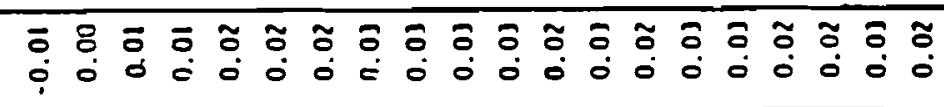 \\
\hline & 量 & 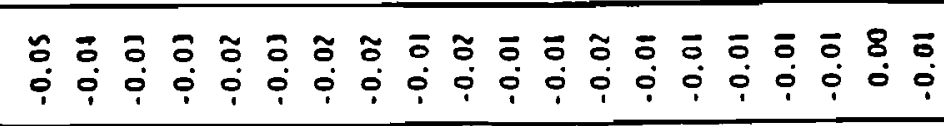 \\
\hline & $\Xi$ & 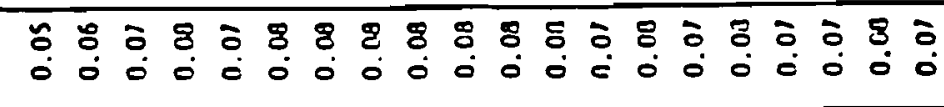 \\
\hline & & $\sigma \sigma$ \\
\hline
\end{tabular}

$\frac{1}{3}$

$\stackrel{2}{ \pm}$

4

등

$\Xi$

$\frac{0}{3}$

章

능

$\frac{\square}{8}$

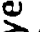

入

离

$\pi$

五

弟

¿

논

$\Xi$

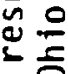

$\stackrel{\infty}{\infty}$

号

$\approx=$

울을

ฮั

$\frac{n}{3}$

인

हू ह

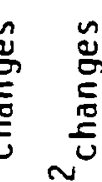

$\ddot{\sigma}$

岕 


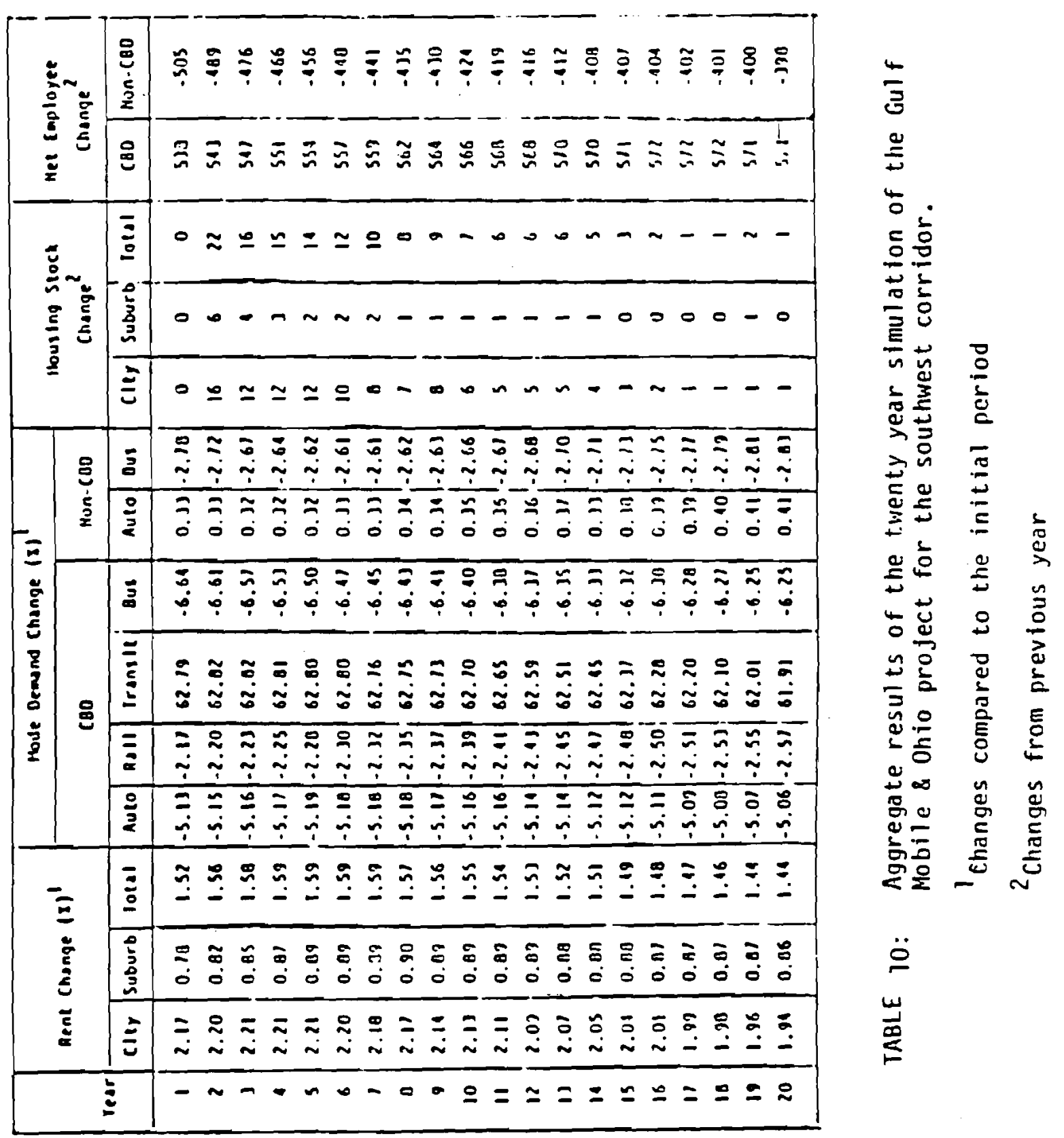




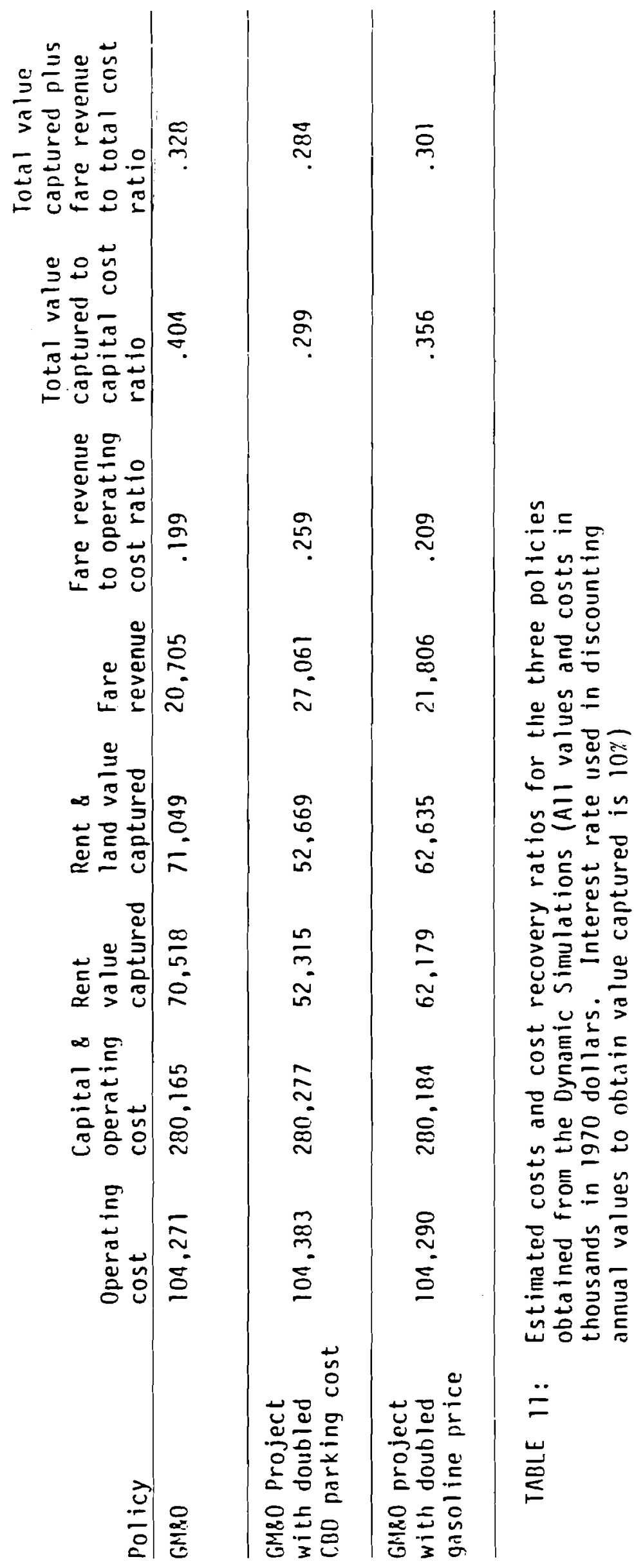

